\title{
MONOTONIC NON-LINEAR ANALYSIS OF REINFORCED CONCRETE KNEE JOINTS USING STRUT-AND-TIE COMPUTER MODELS
}

\author{
N.H.T. To ${ }^{1}$, J.M. Ingham ${ }^{2}$ and S. Sritharan ${ }^{3}$
}

\begin{abstract}
This paper presents the continuation of research considering the analysis of reinforced concrete bridge knee joints subjected to in-plane seismic loads. Strut-and-tie models incorporating rational joint force transfer mechanisms were developed to capture the non-linear inelastic response measured in four largescale bridge knee joint tests. These models corresponded to different joint reinforcement detailing types and were analysed with Drain-2DX using non-linear truss elements. Obtained results were in satisfactory agreement with the measured displacement envelopes.
\end{abstract}

\subsection{INTRODUCTION}

A strut-and-tie model (STM) is a discrete representation of stress fields developed within a reinforced concrete structure that is subjected to external actions. Within a model, the strut and the tie members are used to represent the actual compressive and tensile stress fields respectively. This type of model has long been employed to predict the strength of structural regions, in particular where the assumption of a linear stress-strain distribution is inapplicable. Further development of this methodology [1] has extended the application of STMs to the whole structure, allowing the strength of the entire structure to be examined simultaneously using this modelling procedure. This procedure is also equally applicable when considering the appropriate detailing of complex structural regions.

Although the strut-and-tie methodology is simple to comprehend, it is a surprisingly complex task when applying this technique in the structural analysis. This is because the successful correlation of a STM to actual structural performance requires sufficient knowledge of the internal force transfer mechanism, which is primarily influenced by the selected reinforcement detailing types and the support conditions. Furthermore, variation of the stress path position in some structural members, when at different loading states, imposes additional difficulty in identifying a suitable model for the corresponding structural system. Previous application of this modelling technique has mostly been limited to the prediction of strength, with utilisation of this procedure to capture non-linear inelastic structural response being rather minimal [2]. This paper presents a contribution to the development of a library of verified STMs for different structures with distinct reinforcement detailing types, allowing the non-linear inelastic structural response to be captured.
The investigation reported herein consists of two parts; the first part presents a comprehensive STM formulation procedure for beams and columns, allowing a reasonably accurate prediction of the elastic stiffness and member strength. The second part integrates the suggested model formulation procedure for beams and columns with previously developed knee joint STMs [3], to capture the non-linear inelastic structural response of four large-scale bridge knee joint test units.

The four large-scale bridge knee joint units considered in the current study were constructed using a common column reinforcement detail and were discretised by incorporating the appropriate joint force transfer mechanisms. Test unit reinforcement detailing types included an as-built detail, a repair, an externally post-tensioned retrofit and a redesigned joint. Procedures are suggested for determining the location of strut-and-tie members, and the capacity of unreinforced lap splices. Poorly confined joint struts are also investigated.

As the testing of the knee joint units considered in the current study has been extensively documented $[3,4]$ and is not directly relevant to this investigation, it is not considered in detail. Instead, applicable data is presented where appropriate to assist illustration of the effectiveness of the truss analogy in describing both inelastic structural displacements and internal force demands. It is important to note that the objective of this investigation was not to obtain a nearperfect correlation between structural and model response by repeated regeneration of the STM, but rather to develop a simple procedure for model generation that provides an elegant diagnostic tool.

\subsection{Research Significance}

The purpose of this research was to investigate the capability of strut-and-tie models in capturing the non-linear forcedisplacement response of reinforced concrete bridge knee joint assemblages. Only the monotonic response was

\footnotetext{
${ }^{I}$ Doctoral Candidate, Department of Civil and Resource Engineering, University of Auckland, New Zealand.

${ }^{2}$ C\&CA Lecturer, Department of Civil and Resource Engineering, University of Auckland, New Zealand.

${ }^{3}$ Assistant Professor, Department of Civil and Construction Engineering, Iowa State University, USA.
} 


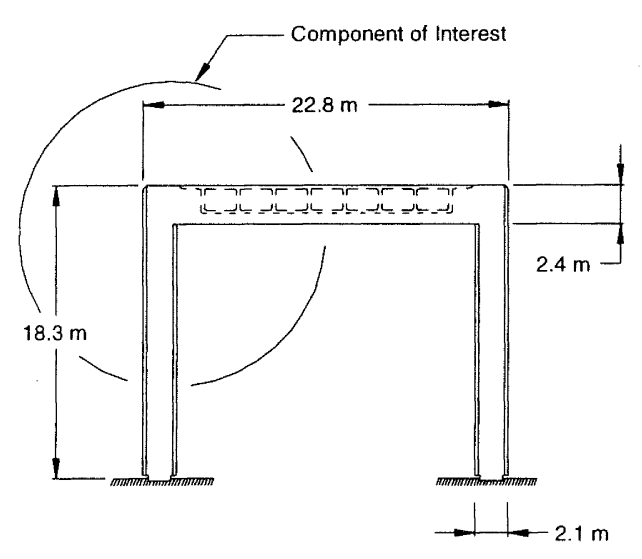

a) - Dimensions of prototype structure.
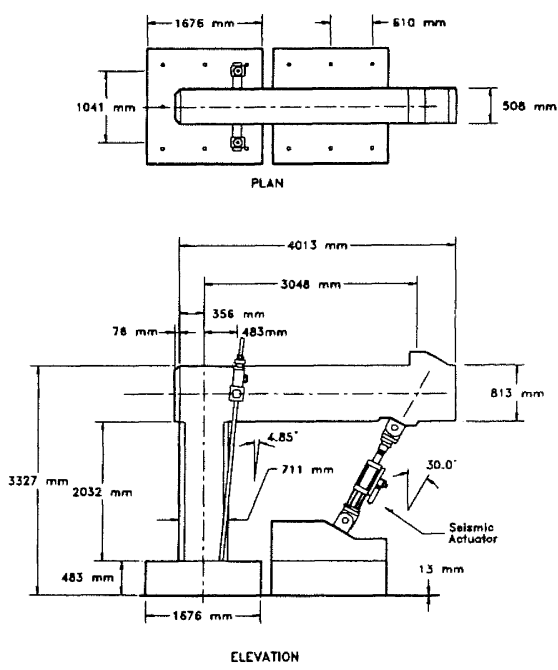

b) - Configuration of test set-up.

Figure 1. Prototype structure and the corresponded test layout.

considered here, but it is expected that this research will be extended to investigate the cyclic response of structures subjected to time history earthquake loading. The goal is to establish a robust procedure to conduct time history analysis for a variety of structural types using STMs. Furthermore, the eventual strategy is to identify if this analysis technique may become significantly more practical through providing synergies linking analysis and design.

\subsection{PROTOTYPE STRUCTURE AND TEST UNIT CONFIGURATION}

Test unit details were based on those of Bent 38 of the I-980 southbound connector in Oakland, California. Dimensions of the prototype structure and the configuration of test units are illustrated in Fig. 1a and Fig. 1b respectively. Figures shown here are intended to provide minimal details of the experiment layout, and readers are referred to a previous report [4] for more thorough information.

\subsection{THEORETICAL CONSIDERATIONS}

In this section a number of theoretical aspects of structural response are considered when generating the rational STM and assessing the demand upon various components within the model.

The procedure adopted in the current study to develop a suitable STM was firstly to identify the Bernoulli (B-)

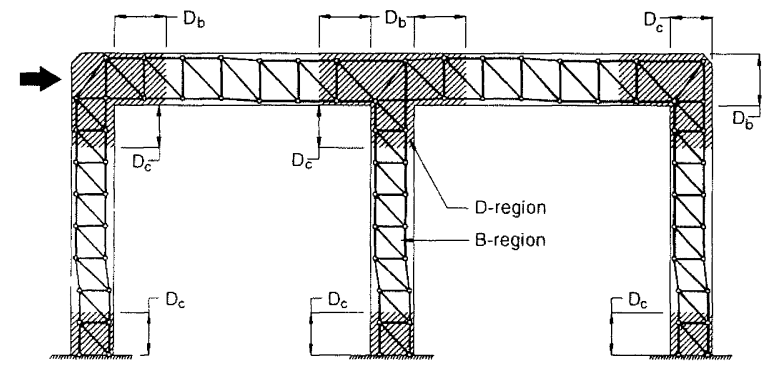

Figure 2. B- \& D-regions in a multi-column reinforced concrete frame. regions and the disturbed (D-) regions within a reinforced concrete structure. Definition of the two regions is given in Fig. 2 using a multi-column reinforced concrete frame. This categorisation is required because the structural members residing in these two regions demonstrate distinctly different response and thus should be treated separately in the STM formulation procedure.

For the structural elements located in B-regions, such as those on the beam and the column members of the test units, a comprehensive section force analysis based upon the Bernoulli compatibility condition that plane sections remain plane was performed. Realistic non-linear stress-strain characteristics for the confined and unconfined concrete were accounted for using the model proposed by Mander et al. [5]. The non-linear characteristics of the longitudinal reinforcement were also considered, as were aspects such as non-regular section geometry and the exact location of the longitudinal reinforcement. In addition, coupling between the applied seismic moment and the corresponding seismic axial force acting on the section was also taken into account.

Since the STM is a discrete representation of the stress flow inside a reinforced concrete structure, it is logical that the model members are placed at the centre of the respective stress path. Although the theory is simple, the major obstacle arises from the fact that the position of sectional force centroids varies both along the member and for the different loading states. This is especially the case for the position of the tension centroid in a section with longitudinal reinforcement distributed approximately uniformly over the section, such as for the column member utilised in the test units considered here, see the inset in Fig 3c.

\subsection{STM in B-region}

In the current study, the longitudinal struts and ties of the beam or column STMs are located at the corresponding flexural force centroids computed at the first-yield state. The first yield state was defined by the commencement of rebar yielding or the extreme concrete fibre reaching a strain value 


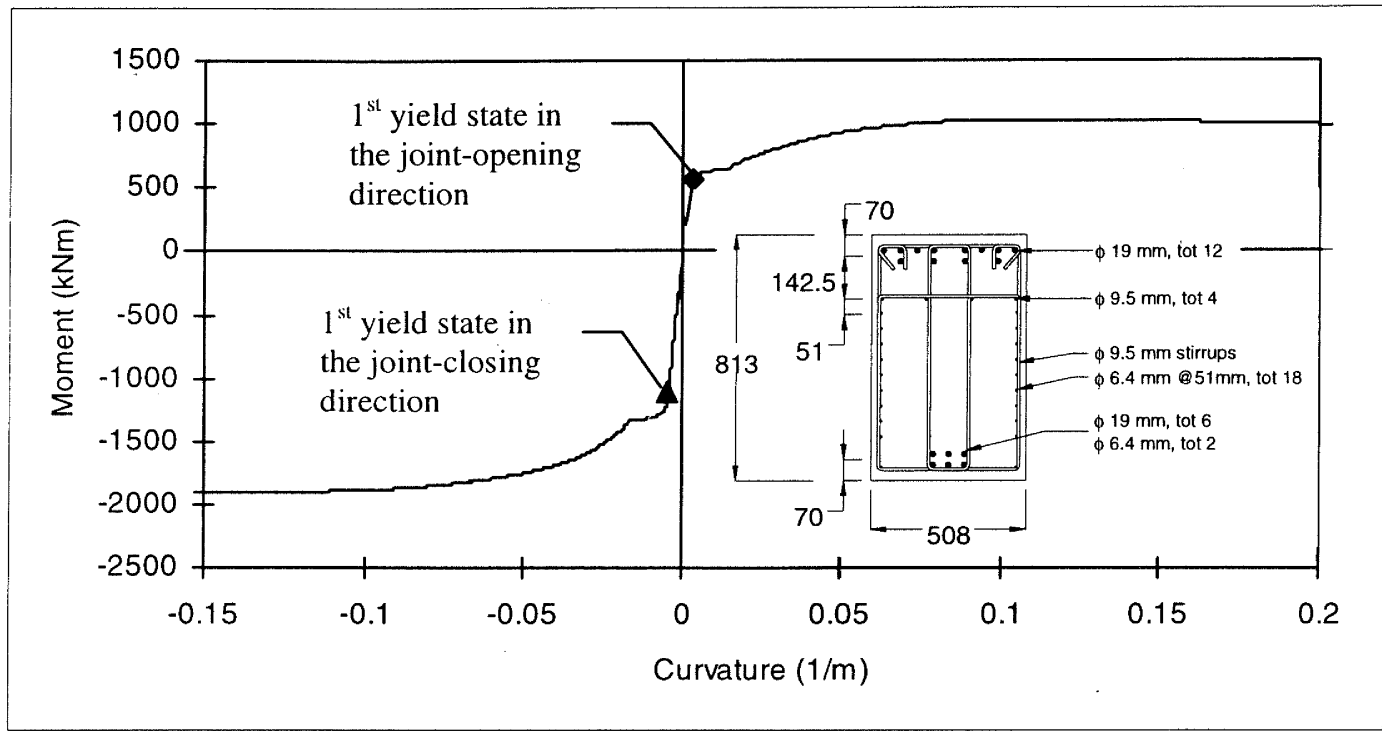

a) Moment-curvature relationship of knee-joint beam section for the as-built, repair and retrofit unit.

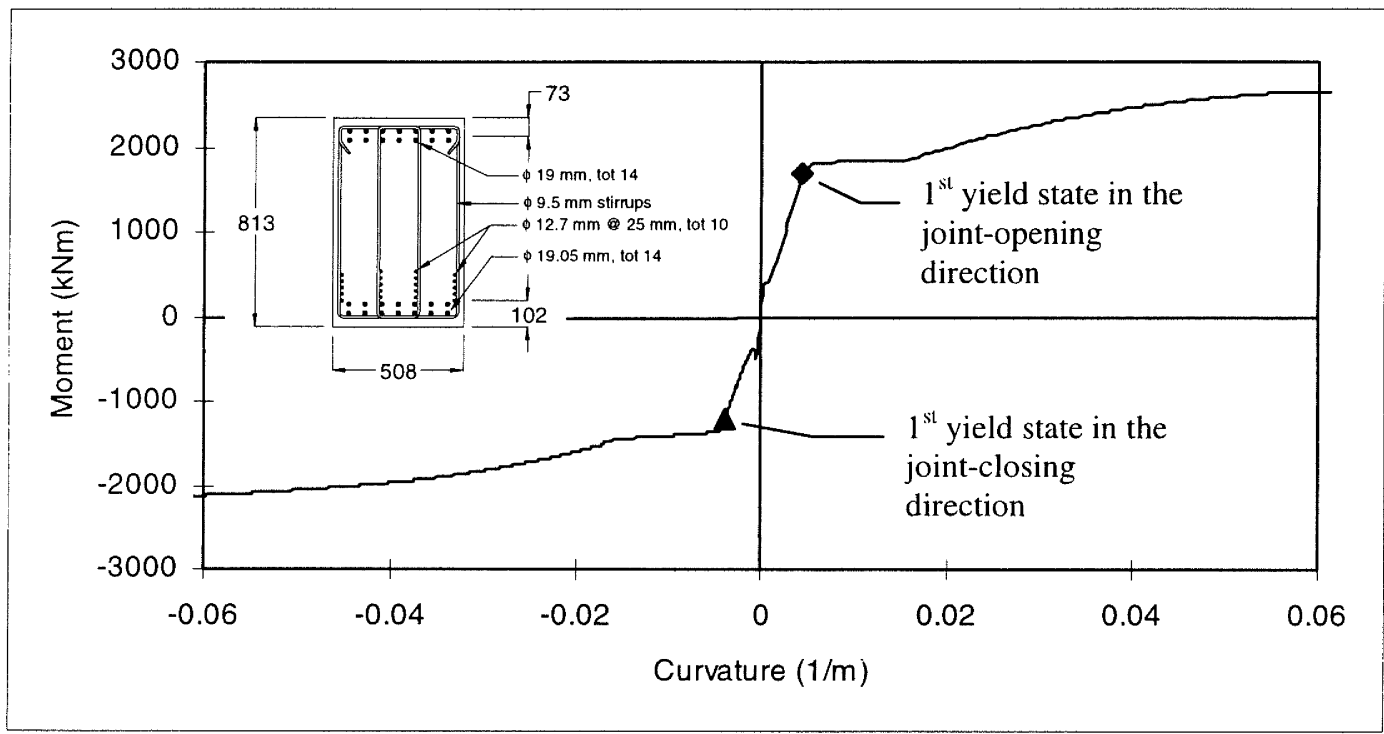

b) Moment-curvature relationship of knee-joint beam section for the redesign unit.

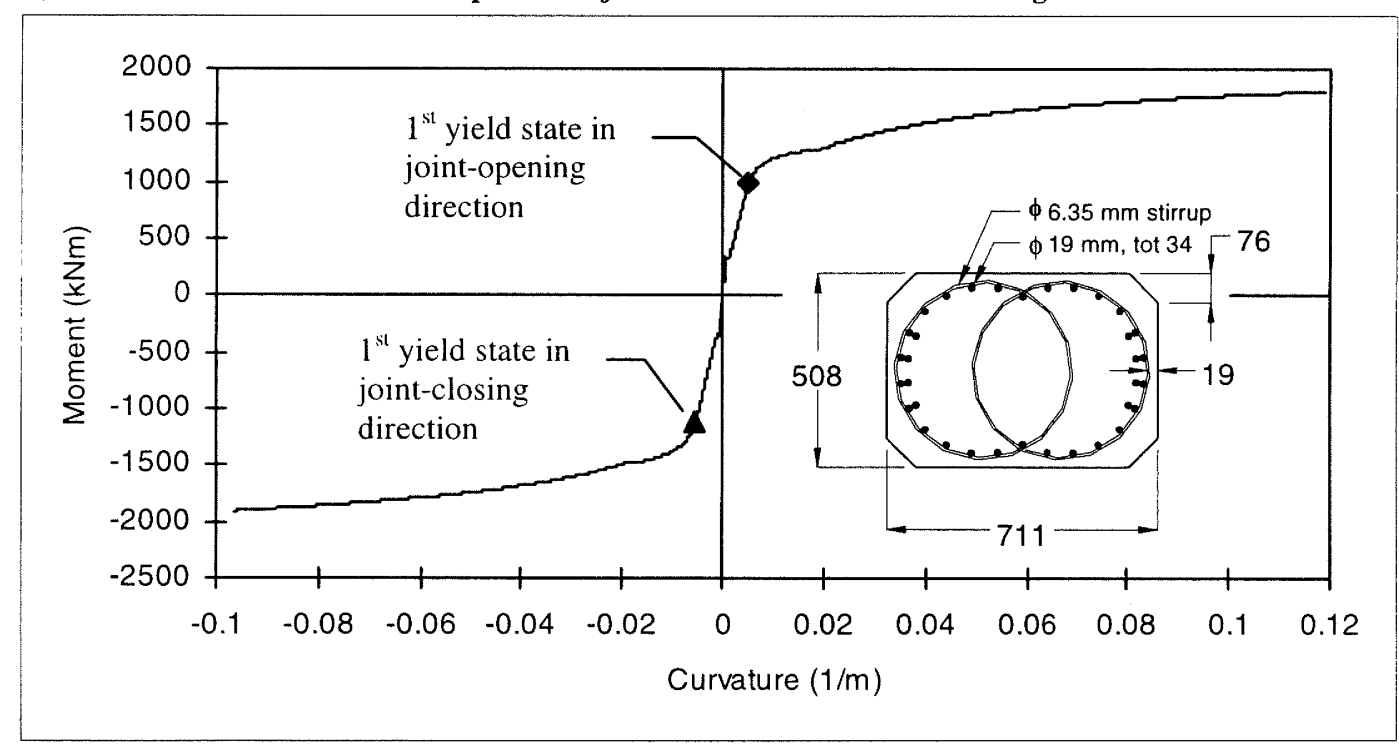

c) Moment-curvature relationship of knee-joint column section for all test units.

Figure 3. Moment-curvature relationships for the beam and column sections. 


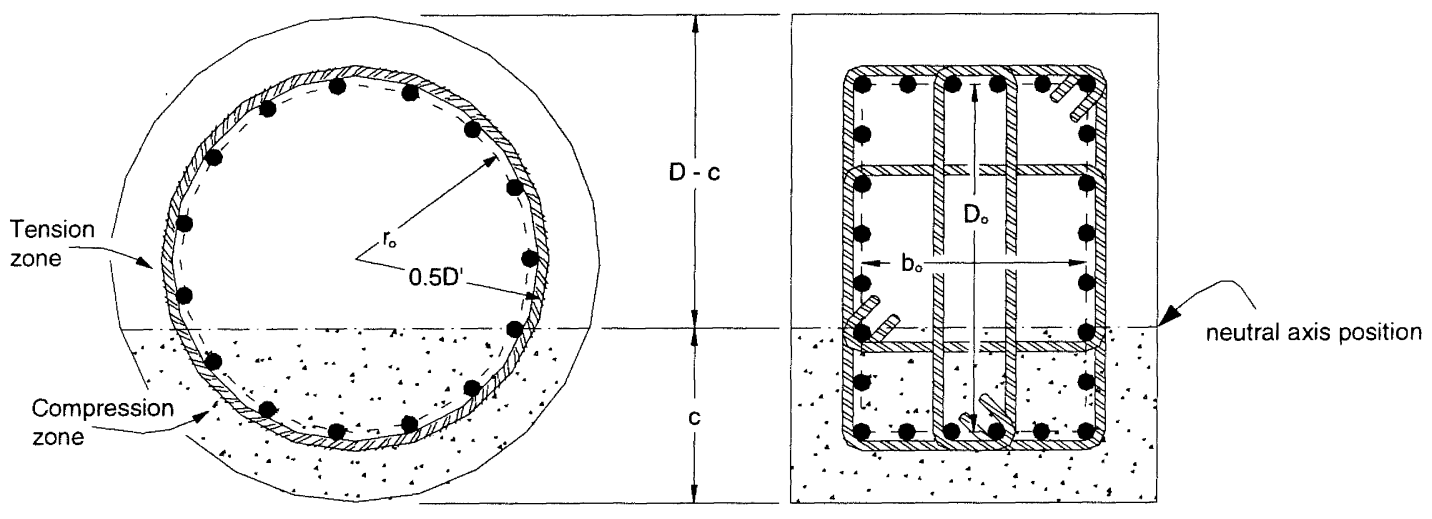

a) A typical circular and rectangular column section.
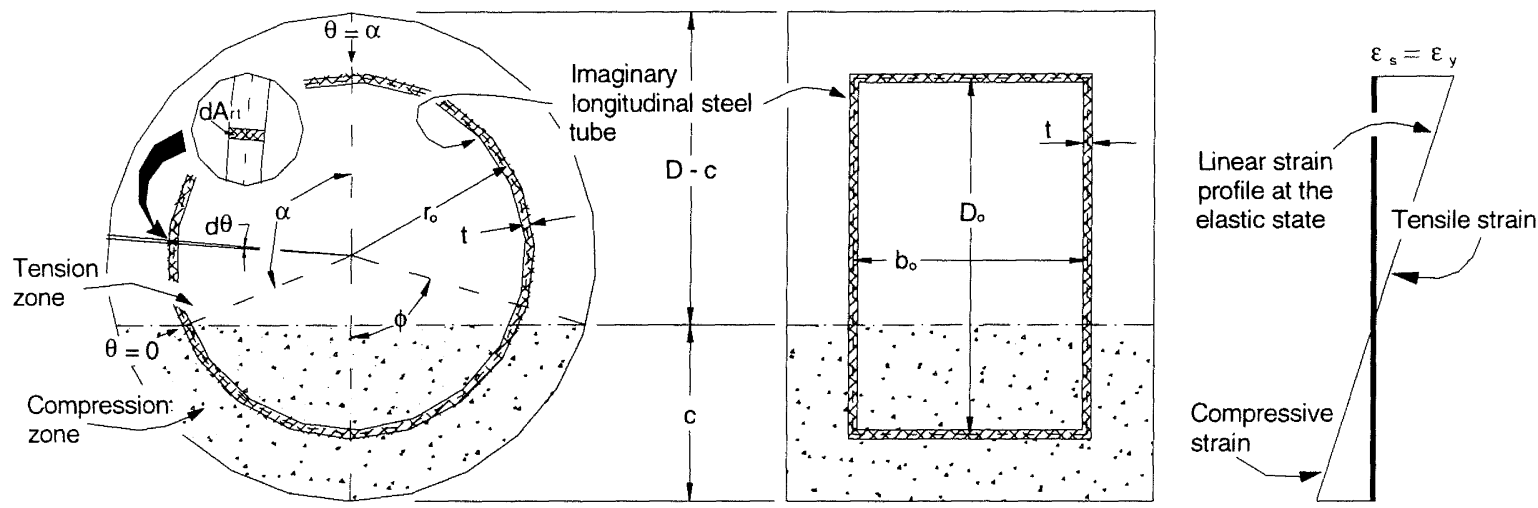

b) The corresponding column sections with imaginary longitudinal steel tube.

Figure 4. Circular and rectangular column sections.

of 0.002 , whichever occurred first. The first yield state was selected because this effectively defines the cracked-section elastic stiffness, after which non-linear behaviour begins (see Fig. 3 for the moment-curvature characteristic of the beam and column members employed in this study). Also, this selection effectively models the flexural force centroidal position over the cracked elastic section. The assumption results in effective modelling of the elastic stiffness, which is essential in ductile design in order to accurately establish the yield displacement accurately, which then dictates ductility demand and capacity computation. It should be noted that the centroidal positions at the first yield state and at the ultimate limit state are different, so that only one of these two positions can be modelled. It is however possible to account for the change in structural response as a result of alteration in the centroidal positions and the material stress-strain characteristics, in conjunction with accounting for the postyield material properties of the model elements.

\subsubsection{Concrete strut and steel tie areas}

In the current study, the cross-sectional area of struts which represent the concrete flexural compression zone, $A_{c s}$, were defined by the area between the neutral axis position and the extreme compression edge of the section:

$A_{c: s}=c b_{w}$

where $c$ is the neutral axis depth;

$b_{w}$ is the section web width.
Column members usually have the longitudinal rebars approximately uniformly distributed adjacent to the perimeter of the section. For simplicity of calculating the effective strength and area of the ties representing the longitudinal tension reinforcement, an imaginary steel tube was assumed to be located within the inner face of the peripheral transverse spiral or hoop, see Fig 4 . The half angle of the flexural tension sector, $\alpha$, and the thickness of longitudinal steel tube, $t$, defined in Fig. $4 \mathrm{~b}$ were calculated using Eq. $2 \mathrm{a}$ and $2 \mathrm{~b}$ respectively.

$\alpha=\cos ^{-1}\left(\frac{2 c-D}{D^{\prime}-d_{b}-d_{v s}}\right)$

for circular column sections

$t=\frac{A_{s t}}{2 \pi r_{t}}$

where $r_{o}=\frac{D^{\prime}-d_{b}-d_{v s}}{2}$

for rectangular column sections

$$
t=\frac{A_{s t}}{2 \cdot\left(b_{0}+D_{o}\right)}
$$

where $D$ is the total sectional depth for rectangular column or total sectional diameter for circular column;

$D^{\prime}$ is the circular concrete core diameter measured from centre to centre of peripheral hoop;

$d_{b}$ is the rebar diameter; 
$d_{v s}$ is the sectional diameter of transverse rebar;

$A_{s t}$ is the total area of longitudinal rebars;

$r_{0}$ is the radius of circular concrete core measured from the section centre to the centreline of the longitudinal rebar, see Fig. $4 \mathrm{~b}$;

$D_{o}$ is the depth of rectangular concrete core measured from the centreline to centreline of the longitudinal rebar along the section height, as defined in Fig. 4b;

$b_{0}$ is the width of rectangular concrete core measured from centreline to centreline of the longitudinal rebar along the section width, as defined in Fig. 4b.

Accordingly, the areas of ties $A_{r r}$ and $A_{r s}$, representing the respective longitudinal tension and compression reinforcement in a circular or a rectangular column section, were computed using Eq. 3:

for circular column sections

$A_{i t}=2 \alpha t r_{i}$

for rectangular column sections

$A_{17}=t \cdot\left(b_{0}+D_{0}+D-2 c\right)$

for all column section geometries

$A_{r s}=A_{s t}-A_{r t}$

For beam sections designed to resist reversing seismic moments, the longitudinal reinforcement is commonly located adjacent to the tension and compression edges of the section. If the side reinforcement quantity is comparatively minor it may be neglected, resulting in a minimal influence upon the modelling results. Therefore, the areas of ties and struts representing the respective longitudinal tension and compression reinforcement were made identical to the actual rebar area, see Eq. 4:

for beam sections

$A_{r t}=A_{y}$

$A_{r s}=A_{s}^{\prime}$

where $A_{s} \quad$ is the longitudinal tension reinforcement area in a beam

$A_{s}^{\prime} \quad$ is the longitudinal compression reinforcement area in a beam

\subsubsection{Effective strength and stiffness of concrete struts}

In order to determine the effective strength of longitudinal concrete struts located in beam or column members, the maximum concrete flexural compression force developed prior to failure, $C_{c(\max )}$, was first evaluated using a section force analysis. The magnitude of this parameter is dependent upon the longitudinal reinforcement quantity and the applied axial load ratio. Section failure was defined by either the longitudinal reinforcement reaching a tensile strain of 0.15 or the extreme fibre of the confined concrete core reaching the maximum compressive strain permitted by Mander's model [5], whichever occurred first. The effective strength of struts representing the concrete in the flexural compression zone, $f_{d}$, was then calculated using Eq. 5:

$f_{d l}=\frac{C_{c(\max )}}{A_{c \cdot s}}$
The Youngs modulus of concrete, $E_{c}$, was calculated following the suggested equation in Eurocode 2 [6]:

$$
\begin{aligned}
& E_{c}=9500\left(f_{c}^{\prime}+8\right)^{1 / 3} \quad \mathrm{MPa} \\
& \text { where } f_{c}^{\prime} \quad \text { is the unconfined concrete } \\
& \\
& \text { strength, }(\mathrm{MPa})
\end{aligned}
$$

This equation was preferred to that recommended in NZS 3101:1995 [7] because it provides a comparable estimation to the actual value, rather than a suitable design solution.

\subsubsection{Effective strength and material properties of reinforcement ties}

When computing an effective yield strength for the ties representing the longitudinal tension reinforcement, it is necessary to correlate the STM member force to the actual sectional action at the first yield state.

For a typical ductile beam with minimal side reinforcement, designed to resist reversing seismic actions, the total flexural tension force at the first yield state is approximately equal to the product of the tension reinforcement area and the reinforcement yield strength. It is therefore appropriate to use the measured yield strength for the ties representing the longitudinal tension reinforcement in a beam STM.

For a column STM, use of the actual yield strength for modelling of longitudinal tension reinforcement is not appropriate due to the strain gradient shown in Fig. 4b. Instead, the effective yield strength of ties representing longitudinal column tension reinforcement, $f_{\mathrm{cy}}$, was computed using Eq. 7:

$f_{e y}=\frac{T}{A_{r t}}$

where $T$ is the total steel tension force when the extreme rebar begins yielding;

As illustrated in Fig. 4b, $T$ for the circular section was calculated as:

$$
\begin{aligned}
T & =2 \int_{\theta=0}^{\theta=\alpha} \sigma_{s} \cdot d A_{r t} \\
& =\frac{f_{y} t\left(D^{\prime}-d_{v s}-t\right)}{\cos \left(\frac{\pi-\alpha}{2}\right) \cdot \sin \left(\pi-\frac{\alpha}{2}\right)} \\
& \cdot \int_{\theta=0}^{\theta=\alpha} \cos \left(\frac{\pi-\theta}{2}\right) \sin \left[\pi-\alpha+\frac{\theta}{2}\right] \cdot d \theta \\
& =\frac{f_{y} t r_{o} \cdot(\sin \alpha-\alpha \cdot \cos \alpha)}{\cos \left(\frac{\pi-\alpha}{2}\right) \cdot \sin \left(\pi-\frac{\alpha}{2}\right)}
\end{aligned}
$$

where $\sigma_{s}$ is the stress function along the imaginary longitudinal steel tube, assuming a linear stress-strain distribution profile as shown in Fig. 4b;

$f_{\mathrm{y}}$ is the measured rebar strength.

By incorporating $A_{r t}$ calculated from Eq. 3a into Eq. 7b, the effective yield strength of ties representing tension reinforcement in the circular column section is:

$$
f_{\ell y}=f_{y} \cdot \frac{\sin \alpha-\alpha \cos \alpha}{2 \alpha \cos \left(\frac{\pi-\alpha}{2}\right) \cdot \sin \left(\pi-\frac{\alpha}{2}\right)}
$$


For rectangular column sections, $T$, was calculated as:

$T=f_{1} t \cdot\left(b_{0}+0.5 D_{0}+0.5 D-c\right)$

Again, by incorporating $A_{r t}$ calculated from Eq. $3 \mathrm{~b}$ into Eq. $7 \mathrm{~d}$, the effective yield strength of ties representing tension reinforcement in the rectangular column section is:

$f_{e y}=f_{y} \cdot \frac{b_{0}+0.5 D_{o}+0.5 D-c}{b_{o}+D_{o}+D-2 c}$

For the elastic modulus of ties representing the longitudinal reinforcement, the commonly assumed value of Young modulus, $E_{s}=200 \mathrm{GPa}$, was employed in the strut-and-tie analyses.

The strain hardening ratio (s.h.r.) of ties representing longitudinal reinforcement was assessed by correlating the moment-curvature relationship of the beam and column sections, evaluated using section force analysis, see Fig. 3 , with that exhibited by the STM truss bay located at the corresponding position. It was found that s.h.r $=2.5 \%$ was suitable for ties representing longitudinal reinforcement located in columns and in beams having significant side reinforcement, but that s.h.r. $=5.0 \%$ was appropriate for ties representing longitudinal reinforcement located in beams without significant side reinforcement.

It is noteworthy that the procedure provided above can equally be applied to other column section geometries. For the column cross-section employed in this study, see inset in Fig. 3c, modelling of longitudinal reinforcement using an equivalent rectangular tube was more appropriate due to the rebar arrangement.

\subsubsection{Analytical charts for beam and column members}

It has been shown that formulation of the STM for beam and column members relies heavily upon the section force analysis. For the case when a comprehensive section force analysis is not available, or if the scope of the exercise is such that a high degree of accuracy is not required, the previously described procedure can be executed using the figures shown in Appendix B. Note that the analytical data plotted on these figures were smoothened with trend lines for ease of application. Figures for the neutral axis depth and the force centroid position were normalised with respect to the total section depth for a beam or a rectangular column section and were plotted for two concrete strengths, $30 \mathrm{MPa}$ and 40 $\mathrm{MPa}$, as a function of longitudinal reinforcement quantities. For the figures detailing the effective strength of concrete struts, strength values computed using Eq. 5 were normalised to the concrete cylinder strength. Note that the column charts only apply for a rectangular column transversely reinforced by circular spirals or hoops. Other combinations of column shape and transverse reinforcement detailing types may require additional analyses.

Grade 60 rebar, with respective nominal yield and ultimate strengths of $413 \mathrm{MPa}$ and $600 \mathrm{MPa}$, was employed in the computation of the analytical charts. These charts can be satisfactorily used for grade 430 steel, which is commonly used in New Zealand, as insignificant discrepancy of the respective analytical values were observed. However, regeneration of the section force analyses is required for other reinforcement grades.

\subsubsection{Diagonal concrete struts}

The strut area representing the concrete between diagonal cracks in beam or column members was computed by multiplying the perpendicular distance between the strut members and the web sectional width. The inclined angle between the strut and the longitudinal axis, $\theta$, was chosen in accordance with the limit suggested by CEB-FIP [8] of between $31^{\circ}$ and $59^{\circ}$, see Fig. 7b. It was shown by Kim and Mander [9] that the inclined angle can either be varied or kept constant along the STM without significant discrepancy in the analytical results. Various researchers have investigated the use of different $\theta$ values, as depicted in Fig. $7 \mathrm{~b}$, when developing truss models $[9,10 \& 11]$ but there remains no definitive conclusions on the appropriate rules to apply to a general condition. The authors have no data supporting a specific recommendation for the strut angle However, as a STM with finer chord discretisation may give improved correlation to the observed flexural response, this policy was adopted throughout the current study when modelling beam and column members.

Accordingly, the models in the strut-and-tie analyses presented here were formulated in such a way that the maximum possible number of truss-bays was incorporated while the angle between the diagonal strut and the member longitudinal axis was kept within the CEB-FIP [8] limits.

An empirical value of $0.85 f^{\prime}$. was adopted here as the upper bound of the effective compressive strength for the diagonal concrete struts. This value is justified in a later section.

\subsubsection{Transverse steel ties}

The transverse ties in the STM represent the secondary rebar in the actual structural members, which are responsible for carrying the member shear force. For the column section transversely reinforced with spiral or circular hoops, the steel contribution to the member shear strength, $V_{s}$, was computed using the proposed equation by Ang et al., [12] in conjunction with consideration of the inclined angle of the diagonal concrete struts, to give:

$V_{s}=\frac{\pi D^{\prime}}{2 s \cdot \tan \theta} A_{v s} f_{v y}$

where $A_{t: s}$ is the cross-sectional area of transverse reinforcement;

$f_{i y}$ is the tensile strength of transverse reinforcement;

$D^{\prime}$ is the circular concrete core diameter measured from centre to centre of peripheral hoop;

$s$ is the longitudinal distance between transverse reinforcement.

The contribution to the member shear strength provided by the concrete was calculated using the recommended equation in NZS 3101:1995 [7]. An effective shear area of $A_{e}=0.8 A_{0}$ was employed [11] and the total area of ties, $A_{v}$, which represent the transverse reinforcement was given by:

$A_{v}=\frac{\pi D^{\prime}}{2 s \cdot \tan \theta} A_{v s}+\frac{\left(0.07+10 \rho_{w^{\prime}}\right) \sqrt{f_{c}^{\prime}}}{f_{v y}} A_{\iota}$

but $0.08 \leq\left(0.07+10 \rho_{w}\right) \leq 0.2$

where $\rho_{w}$ is the area ratio of longitudinal tension reinforcement to gross sectional area. 


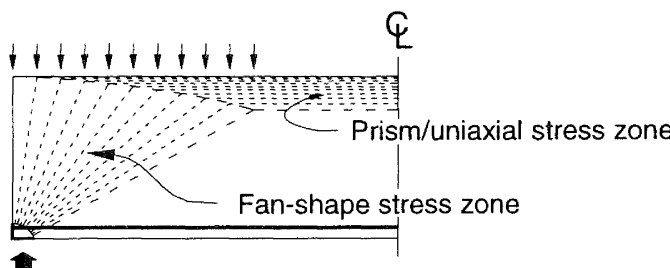

a) Stress distribution in a simply

supported reinforced concrete beam.

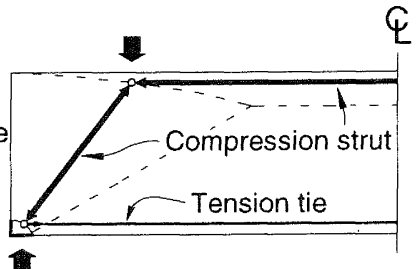

b) STM representation of a simply

supported reinforced concrete beam.
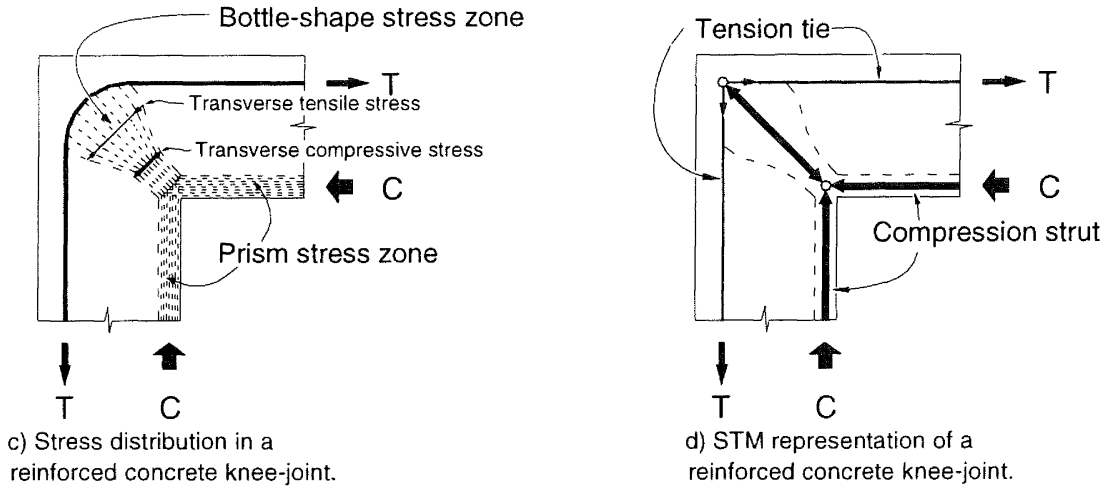

Figure 5. Compressive stress distributions in reinforced concrete structures.

For the member shear strength provided by rectangular ties, the equation recommended by NZS 3101:1995 [7] was used in conjunction with consideration of the inclined strut angle:

$V_{s}=A_{i: s} f_{i v} \frac{d}{s \cdot \tan \theta}$

where $d$ is the effective member depth

Again, by incorporating the concrete contribution to the member shear strength, the total area of transverse ties was computed as:

$A_{v^{\prime}}=\frac{d}{s \cdot \tan \theta} A_{v: S}+\frac{\left(0.07+10 \rho_{w}\right) \sqrt{f_{c}^{\prime}}}{f_{v y}} A_{\ell}$

but $0.08 \leq\left(0.07+10 \rho_{w}\right) \leq 0.2$

The measured reinforcement strength was employed as the effective yield strength of transverse ties and the commonly assumed Young modulus, $E_{x}=200 \mathrm{GPa}$, was used in the analysis.

\subsection{STM in D-region}

A thorough treatment of the STMs of knee joints with different reinforcement detailing has been documented previously $[3,4]$. Since these models were implemented directly as previously reported, their formulation is not considered further in this paper. However relevant features regarding the determination of area and effective strength of the strut and tie members, lap splice assessment and reinforcement clamping length are briefly addressed in the following sections.

\subsubsection{Effective strength and stiffness of concrete struts and steel ties}

The compressive stress field developed within a reinforced concrete structure is highly influenced by any confining effects arising from the $\mathrm{D}$-region boundary conditions and by the extent of cumulative damage to the concrete. Despite these influential factors, the stress field can approximately be classified into three categories with the aid of the visualised stress trajectories; namely fan-, bottle- and prism-shaped stress zones, see Fig. 5. Premature failure resulting in concrete crushing may occur in bottle-shaped stress zones if the stressed region is not transversely reinforced or adequately confined by the surrounding bulk concrete

In addition to the stress distribution characteristic, the effective concrete compressive strength is also governed by the multi-axial stress state and the presence of reinforcement causing transverse tensile strains to be induced in the concrete mass. Various researchers have previously suggested suitable values for the effective concrete compressive strength $[1,10 \& 13]$. These values were later supported by Sritharan [14] when considering joint struts subjected to seismic loading condition, and the values shown in Table 1 were adopted is this study. The value of Young modulus computed using Eq. 6 was adopted for the D-region concrete struts.

For tie members representing either the longitudinal or transverse reinforcement located in D-regions, the measured yield strength was used. Also, the commonly assumed values for steel Young modulus, $E_{s}=200 \mathrm{GPa}$, and s.h.r. $=5.0 \%$, were employed.

In this investigation the cross-sectional area of the concrete struts situated in D-regions was determined graphically while the actual cross-sectional area was used in the tie members representing longitudinal or transverse reinforcement.

\subsubsection{Lap splice assessment}

An assessment procedure has been previously developed for the effectively unreinforced lap splice [ $4 \& 11]$ of the as-built joint, see Fig. 6a. A failure mechanism was presumed to develop between each of the lapped bars in tension, and around the inside perimeter of the bar group, see Fig. $6 \mathrm{~b}$. 


\begin{tabular}{|c|l|}
\hline $\begin{array}{c}\text { Effective } \\
\text { strut } \\
\text { strength }\end{array}$ & \multicolumn{1}{|c|}{ Compressive strut conditions } \\
\hline $0.85 f_{c}^{\prime}$ & $\begin{array}{l}\text { This value is applicable for struts } \\
\text { representing a prism stress distribution, } \\
\text { such as depicted in Figs. 5a and 5c, where } \\
\text { there is minimal transverse tensile strain } \\
\text { induced by neighbouring rebar. }\end{array}$ \\
\hline $0.68 f_{c}^{\prime}$ & $\begin{array}{l}\text { This value can be adopted for struts } \\
\text { locating in regions where minor cracking } \\
\text { is expected, such as struts modelling fan- } \\
\text { shaped stress zones in deep beam } \\
\text { members, see Fig. 5a. }\end{array}$ \\
\hline $0.51 f_{c}^{\prime}$ & $\begin{array}{l}\text { This value is appropriate for concrete } \\
\text { struts when the neighbouring rebar is not } \\
\text { subjected to significant strain hardening. } \\
\text { An example of this application would be } \\
\text { the struts residing in a prestressed joint. }\end{array}$ \\
\hline $0.34 f_{c}^{\prime}$ & $\begin{array}{l}\text { This is the maximum permissible stress } \\
\text { for concrete struts when there is potential } \\
\text { development of significant inelastic strain } \\
\left(\varepsilon_{s}>0.02\right) \text { in the neighbouring } \\
\text { reinforcement. This value can also be } \\
\text { applied to struts modelling bottle-shaped } \\
\text { stress zones when no effective } \\
\text { confinement is provided, see Fig. 5c. }\end{array}$ \\
\hline
\end{tabular}

Table 1. D-region effective compressive strength of strut members [1, 10, $13 \& 14]$.

Assuming the concrete tensile strength across the rupture surface to be $0.29 \sqrt{ } f_{c}^{\prime}$, the lap splice capacity, $T_{t p}[11]$ was:

$T_{\ell p}=0.29 \sqrt{f_{c}^{\prime} \ell_{s}} p_{\ell}$

where $\ell_{s} \quad$ is the lap splice length of the longitudinal rebars;

$p_{t}$ is the cross-sectional length of the rupture surface.

\subsubsection{Reinforcement clamping length}

For knee joints subjected to joint-opening moments, the associated crack pattern does not allow a uniform bond stress along the embedded length of tension reinforcement. When the bond stress along the effective anchorage zone of the column reinforcement is equated to the maximum experimentally observed value of $2.5 \sqrt{ } f_{c}^{\prime}$ (MPa) [3], the effective clamping length, $\ell_{c}$, can be calculated as:

$\ell_{c}=\frac{d_{b} f_{y}}{10 \sqrt{f_{c}^{\prime}}}$

Note that the rebar overstrength factor was not included in Eq. 13, as the model was intended to capture the observed response rather than providing a suitable design solution.

\subsection{EXAMPLE OF BEAM STM FORMULATION}

As an example to demonstrate the STM formulation procedure using the section analysis charts in Appendix B, consider a doubly reinforced cantilever beam as depicted in Fig. 7a [15]. This beam was designed to exceed the shear strength required by the code to enable ductile response. The cantilever beam had an unconfined concrete compressive strength, $f_{\mathrm{c}}^{\prime}=30 \mathrm{MPa}$, compression to tension rebar quantity ratio, $\omega=1.0$ and tension rebar area to gross sectional area ratio, $\rho_{\mathrm{w}}=0.005$. As identified by dashed lines in Fig. B1.1, B1.3 and B1.5 in Appendix B, the first-yield state neutral axis depth, compression centroid and effective concrete compressive strength are $0.215 D, 0.075 D$ and $0.4 f^{\prime}$ c respectively. The area of longitudinal struts representing the concrete flexural compression zone and the flexural compression reinforcement, were calculated using Eq. 1 and Eq. $4 \mathrm{~b}$ respectively. Similarly, the area of ties representing the longitudinal tension reinforcement and the transverse steel were found using Eqs. $4 \mathrm{~b}$ and 11 respectively. The calculated member areas are listed in Table 2.

Also included in the table are the areas of diagonal concrete struts, which were computed according to the procedure detailed in a previous section. Since the beam section had insignificant side reinforcement, s.h.r. $=5.0 \%$ was adopted for the ties representing longitudinal reinforcement.

The formulated STM and the corresponding analytical prediction of the monotonic force-displacement response are illustrated in Figs. $7 \mathrm{~b}$ and $7 \mathrm{c}$ respectively. Two sets of analytical results are shown in Fig. 7c; one was computed according to the analytical charts using nominal material strengths, and the other was computed following a separate section analysis utilising the actual material strengths. It is noted that the two sets of analytical results predicted similar structural response in terms of the effective stiffness and strength, validating utilising of the analytical charts presented in Appendix B when the scope of the analysis is such that a high degree of precision is not warranted.

\subsection{ANALYTICAL MODELLING OF KNEE JOINT TEST UNITS}

In this section, details of four knee-joint test units subjected to both positive and negative applied seismic moments are presented. For the STMs, attention is given to discretisation of the appropriate joint force transfer mechanisms, and the

\begin{tabular}{|c|c|}
\hline Member description & Area \\
\hline Longitudinal concrete strut, $A_{c s}$ & $34830 \mathrm{~mm}^{2}$ \\
\hline Longitudinal rebar strut, $A_{t s}$ & $804 \mathrm{~mm}^{2}$ \\
\hline Longitudinal rebar tie, $A_{r t}$ & $804 \mathrm{~mm}^{2}$ \\
\hline Transverse rebar tie, $A_{v: s}$ & $1220 \mathrm{~mm}^{2}$ \\
\hline Diagonal concrete strut & $87642 \mathrm{~mm}^{2}$ \\
\hline
\end{tabular}

Table 2. Cantilever beam STM member areas. 


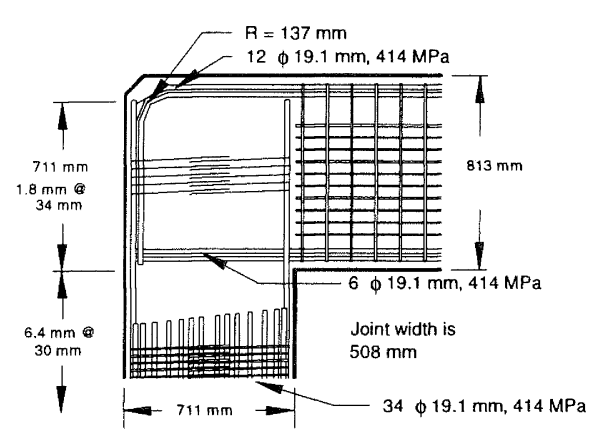

a) As-built joint

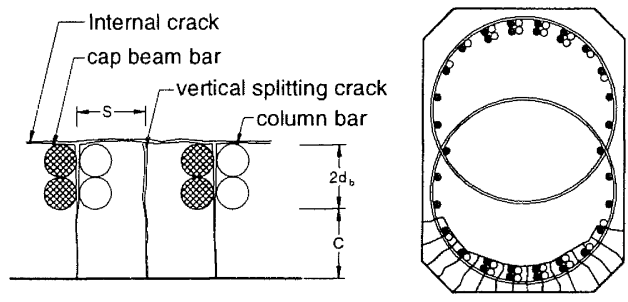

b) Lap splice failure mechanism

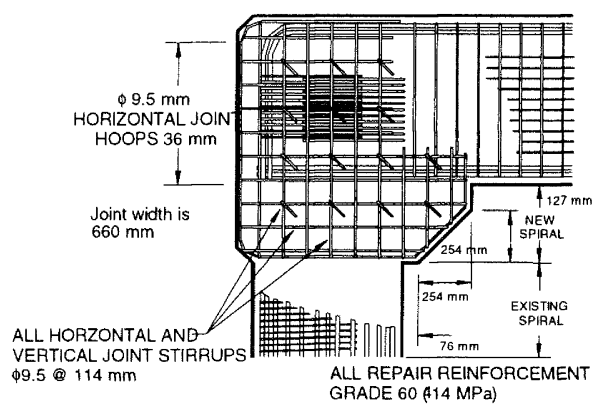

c) Repaired joint

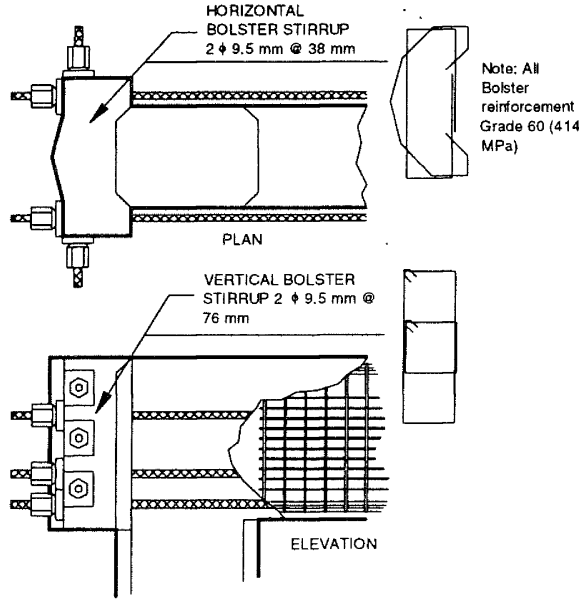

d) Repaired joint

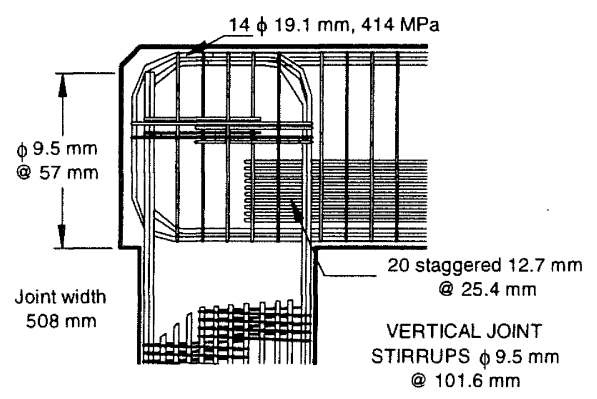

Note: Intermediate longitudinal column reinforcement not shown in the joint zone for clarity.

\section{e) Retrofit joint}

Figure 6. Test units knee-joint details.

implied structural response. Results obtained from the strutand-tie analyses are compared with the recorded structural response, and with that acquired from conventional frame analyses, to determine the effectiveness and the advantage of STMs in capturing various aspects of structural performance. It is noted that all analyses were performed using the actual material strengths. For the STMs representing joint-opening performance, extra concrete struts were added in tandem with the longitudinal rebar ties located in the beam and column members. This was done to avoid excessive initial vertical displacement resulting from the application of joint-closing dead load prior to joint-opening seismic moments. The area of these extra concrete struts was selected as half of the section area.

The beam gravity load in the planar frame model was applied as a uniformly distributed load along the member, while half of the column weight was applied as a lump mass to the top column node. In the STMs, the self-weight of beams and columns was resolved into equivalent point loads and then applied at the appropriate nodal positions.

\subsection{Conventional frame analysis}

The planar frame models of the four test units, as illustrated in Fig. 8, were developed along the member centerlines, consisting of beam and column elements with effective member properties. The effective flexural stiffness, $E I_{e}$ of the beam and column members was established using Eq. 14:

$E I_{e}=\frac{M_{y}^{l s t}}{\phi_{y}^{l s t}}$

where $M^{l s t}{ }^{\prime}$ is the moment at the first yield state $\phi^{\prime s t}{ }_{y} \quad$ is the curvature at the first yield state

The effective axial stiffness, $E A_{\ell}$, was computed using Eq. 15 [11], to reflect the influence of axial load and longitudinal reinforcement:

$$
\begin{gathered}
E A_{e}=E A_{g} \frac{E I_{e}}{E I_{g}} \\
E A_{g} \quad \text { is the gross axial stiffness } \\
E I_{g} \quad \text { is the gross flexural stiffness }
\end{gathered}
$$

The calculated effective member properties for the frame analysis are listed in Table 3.

All four frame models illustrated in Fig. 8 had the beam and column members connected to joint-links at the corresponding beam-joint and column-joint interfaces. These interface nodes are typically placed at this location to capture the maximum bending moment sustained by the members. These joint links were assigned the effective member properties listed in Table 3 to represent yield penetration into 

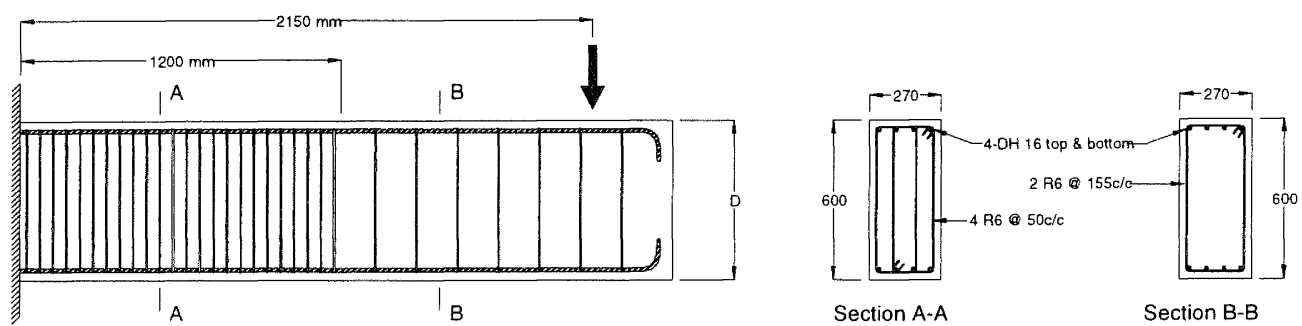

a) Reinforcement detail of the cantilever beam

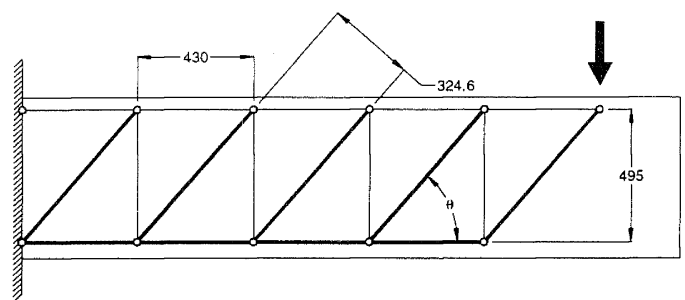

b) STM of the cantilever beam

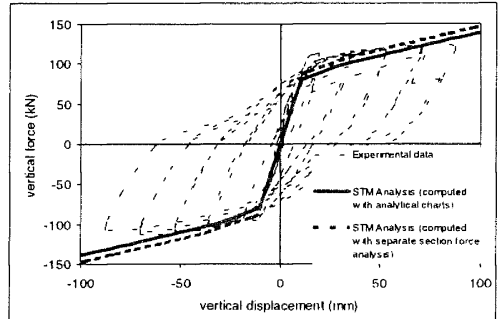

c) Force-displacement response

Figure 7. The STM formulation example of a cantilever beam.

the joint region, and had a large flexural strength in order to avoid the formation of a plastic hinge within the joint panel. The length of the joint links was calculated using Eq. 16 [11], corresponding to yield penetration, $\ell_{p j}$, of the beam and column longitudinal reinforcement into the joint:

$1_{p i}=0.022 f_{y} d_{b}$

Rigid joint blocks were employed in the model to provide geometric connectivity and compatibility between beam and column members at the end of the joint-links.

\subsection{Strut-and-tie modelling and analytical results}

This section provides details of four knee joint STMs that were developed using the suggested STM formulation procedure. In all cases the STMs employed in this study were based on those previously recommended by Ingham et al. [3].

\subsubsection{As-built unit}

The knee joint reinforcement detail of the as-built test unit is illustrated in Fig. 6a. The column longitudinal reinforcement was not fully extended to the top of the joint region and was terminated with straight extension, implying the absence of an effective end anchorage mechanism. As a consequence, for joint-opening actions the compression force entering the joint region from the beam member was diverted from the original flexural compressive stress path to connect with the column longitudinal reinforcement at a distance from the bar end identical to half of the calculated clamping length given by Eq. 13. This feature was incorporated into the as-built joint-opening STM as depicted in Fig. 8b. Also in the STM, due to diversion of the compressive stress path, the internal lever arm at the beam-joint interface was shortened, which effectively reduced the beam flexural strength and member stiffness. Since the joint panel was unreinforced and the

\begin{tabular}{|c|c|c|}
\hline Member & $E I_{\theta}\left(M N m^{2}\right)$ & $E A_{e}(M N)$ \\
\hline $\begin{array}{l}\text { As-built/Repair column } \\
\text { subjected to joint-opening } \\
\text { moment }\end{array}$ & 195.5 & 4491.5 \\
\hline $\begin{array}{l}\text { As-built/Repair column } \\
\text { subjected to joint-closing } \\
\text { moment }\end{array}$ & 210.0 & 4824.6 \\
\hline $\begin{array}{l}\text { Retrofit column subjected to } \\
\text { joint-opening moment }\end{array}$ & 197.5 & 4537.5 \\
\hline $\begin{array}{l}\text { Retrofit column subjected to } \\
\text { joint-closing moment }\end{array}$ & 210.6 & 4838.5 \\
\hline $\begin{array}{l}\text { Redesign column subjected to } \\
\text { joint-opening moment }\end{array}$ & 203.5 & 4675.3 \\
\hline $\begin{array}{l}\text { Redesign column subjected to } \\
\text { joint-closing moment }\end{array}$ & 224.7 & 5162.4 \\
\hline $\begin{array}{c}\text { As-built/Repair beam subjected } \\
\text { to joint-opening moment }\end{array}$ & 148.4 & 2694.0 \\
\hline $\begin{array}{c}\text { As-built/Repair beam subjected } \\
\text { to joint-closing moment }\end{array}$ & 265.5 & 4819.8 \\
\hline $\begin{array}{l}\text { Retrofit beam subjected to } \\
\text { joint-opening moment }\end{array}$ & 273.2 & 4960.0 \\
\hline $\begin{array}{l}\text { Retrofit beam subjected to } \\
\text { joint-closing moment }\end{array}$ & 378.0 & 6864.8 \\
\hline $\begin{array}{l}\text { Redesign beam subjected to } \\
\text { joint-opening moment }\end{array}$ & 374.5 & 6799.1 \\
\hline $\begin{array}{l}\text { Redesign beam subjected to } \\
\text { joint-closing moment }\end{array}$ & 314.3 & 5706.2 \\
\hline
\end{tabular}

Table 3. Effective member properties. 


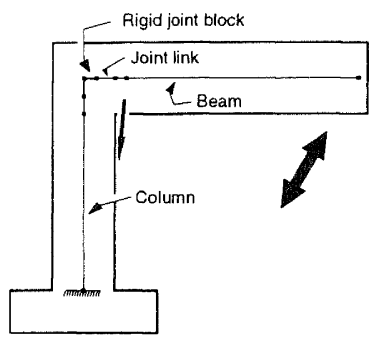

a) As-built unit frame model
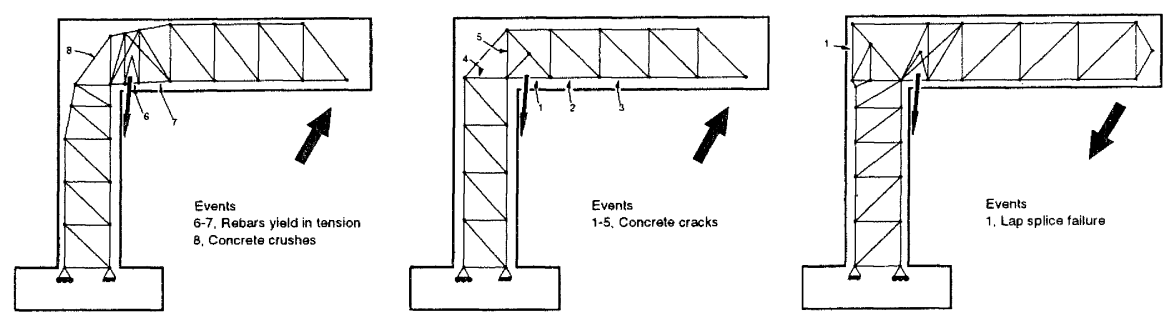

b) As-built unit strength STM in joint-opening direction

c) As-built unit pre-crack STM in joint-opening direction d) As-built unit STM in joint-closing direction

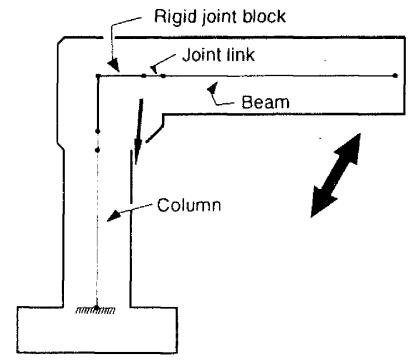

e) Repair unit frame model

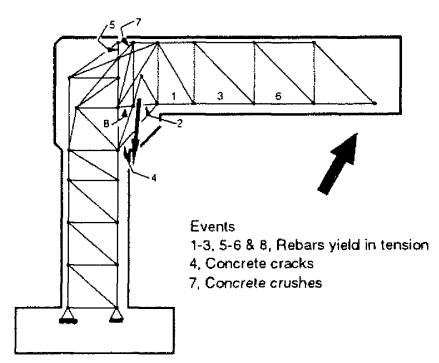

f) Repair unit STM in joint- opening direction

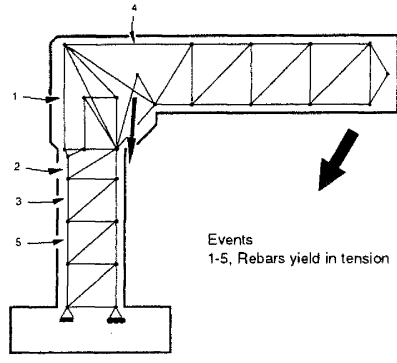

g) Repair unit STM in joint-closing direction

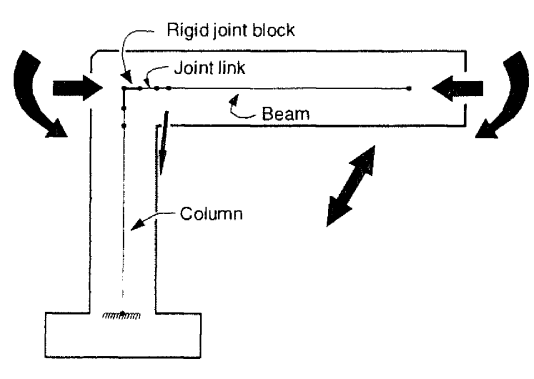

h) Retrofit unit frame model

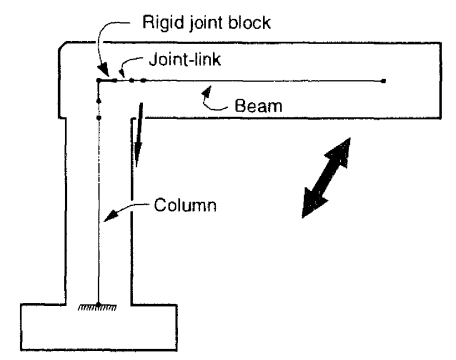

k) Redesign unit frame model

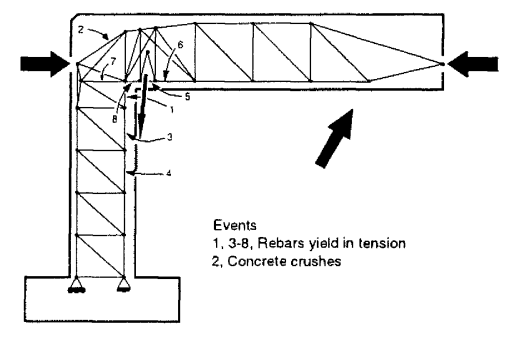

i) Retrofit unit STM in joint-opening direction

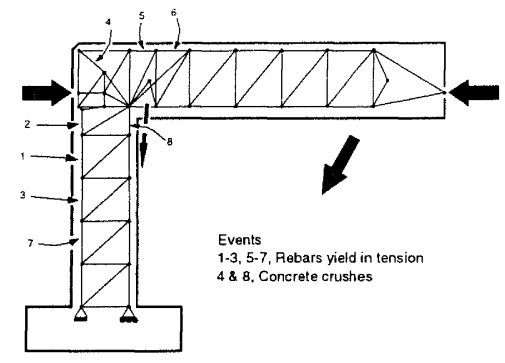

j) Retrofit unit STM in jointclosing direction

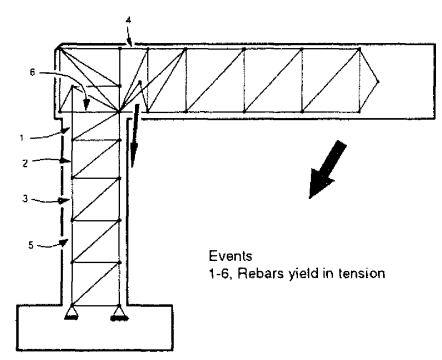

m) Redesign unit STM in jointclosing direction

Figure 8. Strut-and-tie and frame model of the test units. 
longitudinal reinforcement embedded in the joint region was expected to develop significant inelastic strain, $0.34 f_{c}^{\prime}$, as stipulated in Table 1, was adopted as the effective strength of concrete struts locating in the joint region.

Test unit stiffness in the joint-opening direction, as predicted by the STM shown in Fig. 8b, is illustrated in the upper right quadrant of Fig. 9a using the dash-dotted line. As discussed previously, the strut located at the beam-joint interface was diverted to provide anchorage to the column longitudinal reinforcement. This resulted in a softer predicted stiffness with respect to that measured.

To improve the joint-opening model stiffness prediction, an additional STM was formulated as shown in Fig. 8c. This model resembled the STM illustrated in Fig. 8b, but was formulated based upon the pre-crack force transfer mechanism with the beam compression path not diverted when entering the joint region. Since cracking was not expected in this STM, only concrete struts and concrete ties were employed to represent the respective flexural compression and tension zones. The areas of the longitudinal strut and tie members were calculated as one half the gross sectional area of the corresponding beam or column member. The tie effective strength was computed assuming a concrete tensile strength equal to $0.6 \sqrt{ } f_{c}^{\prime}$, and the strut effective strength was based on a concrete compression strength of $0.85 f^{\circ}$. as stipulated in Table 1. The area and the material properties of other model components, such as the diagonal concrete struts and the ties representing transverse reinforcement, were computed using the procedure previously discussed herein. Since there was no significant side reinforcement in the beam, s.h.r. $=5.0 \%$ was employed for the ties representing beam longitudinal reinforcement and s.h.r. $=2.5 \%$ was used for ties representing column longitudinal reinforcement.

Analytical events captured by the pre-crack model shown in Fig. $8 \mathrm{c}$ suggested that cracking first occurred below the applied dead load; see event 1 in Fig. 8c. As each concrete tie cracked, the analysis was terminated and the STM was regenerated by replacing the cracked concrete tie with a tie representing reinforcement at the corresponding location. Regeneration of the analysis using the pre-cracked STM was continued until cracking developed in all of the concrete ties located in the joint panel. The sequence of crack development in the test unit is depicted by events 2 to 5 in Fig. 8c, suggesting that the joint panel was fully cracked prior to the development of reinforcement plasticity. It should be noted that utilisation of the pre-crack STM was conducted here as an academic exercise to validate the model and to obtain better stiffness prediction in the early elastic domain. However, it is not proposed that this exercise be a standard feature of a regular strut-and-tie analysis.

The analytical events derived from the pre-cracked model were integrated with those captured using the original STM of Fig. $8 \mathrm{~b}$ to produce the full picture of structural response exhibited by the as-built unit. The force-displacement response envelope predicted by the two STMs described above is illustrated using the solid line in the upper right quadrant of Fig. 9a. In comparison to the stiffness predicted earlier by the STM of Fig. $8 b$, this curve indicates a significantly improved correlation to the actual unit stiffness. However, the yield displacement was still not reasonably captured. Relevant analytical events described in Fig. 8b for the joint-opening unit are illustrated by the solid triangles locating on the force-displacement envelope in Fig. 9a. Event 6 indicated that yielding of beam longitudinal reinforcement first occurred below the applied dead load and was followed by yielding of the neighbouring beam longitudinal reinforcement, see event 7 in Fig. 8b. Furthermore, concrete crushing was predicted by event 8 . These analytical events were consistent with experimental observations.

The joint-closing STM for the as-built unit is illustrated in Fig. 8d. From the rupture surface depicted in Fig. 6b, the capacity of the tie representing the lap-spliced reinforcement was calculated using Eq. 12. The residual strength of the lap splice was determined from the experimental data to be $40 \%$ of the maximum value.

For the joint-closing STM, $0.51 f_{c}^{\prime}$ was selected as the effective strength of concrete struts locating at the joint region, primarily because of joint damage expected to develop for joint-opening actions. As for the joint-opening STM, s.h.r. $=5.0 \%$ was employed for the ties representing beam longitudinal reinforcement and s.h.r. $=2.5 \%$ was used in the ties representing column longitudinal reinforcement.

The calculated joint-closing STM response is illustrated by the solid line in the lower left quadrant of Fig. 9a. This result suggests accurate replication of the experimentally recorded inelastic force-displacement response. Only one analytical event, corresponding to lap-splice failure, was captured by the STM in the joint-closing direction, see Fig. 8d, and is identified on the force-displacement envelope by a solid diamond in Fig. 9a. This lap-splice failure was well predicted by the STM. To capture post-failure behaviour, an identical STM was employed with the tensile strength of the tie representing the lap-spliced reinforcement being reduced to $40 \%$ of the maximum unit strength.

In addition to the response derived from the joint-opening and joint-closing STMs, an analysis using the planar frame model shown in Fig. 8a was considered. Since the shortened internal lever-arm at the beam-joint interface could not readily be captured using the planar frame model, overestimation of the unit strength in the joint-opening direction was inevitable, see the dotted line in Fig. 9a. Furthermore, the effective stiffness was not well captured, possibly due to the complexity of the force transfer mechanism in the vicinity of the beam-joint interface. Since lap-splice failure in the joint-closing direction was not predicted using the planar frame model, analytical results had poor correlation with measured unit strength However, the predicted unit stiffness did correlate well with the measured value.

\subsubsection{Repaired unit}

The knee joint reinforcement details of the repaired unit are shown in Fig. 6c. This test unit replicated the repair to bent 38 of the I-980 freeway connector, implemented by the California Department of Transportation following the Loma Prieta earthquake, and was constructed using the damaged asbuilt unit discussed in the previous section. Consequently the test unit shared the same column and beam members as the as-built unit, but the joint region was enlarged by incorporating the joint haunch, and extra reinforcement was introduced to improve joint integrity.

STMs replicating joint force transfer mechanisms for jointopening and -closing actions are respectively illustrated in 


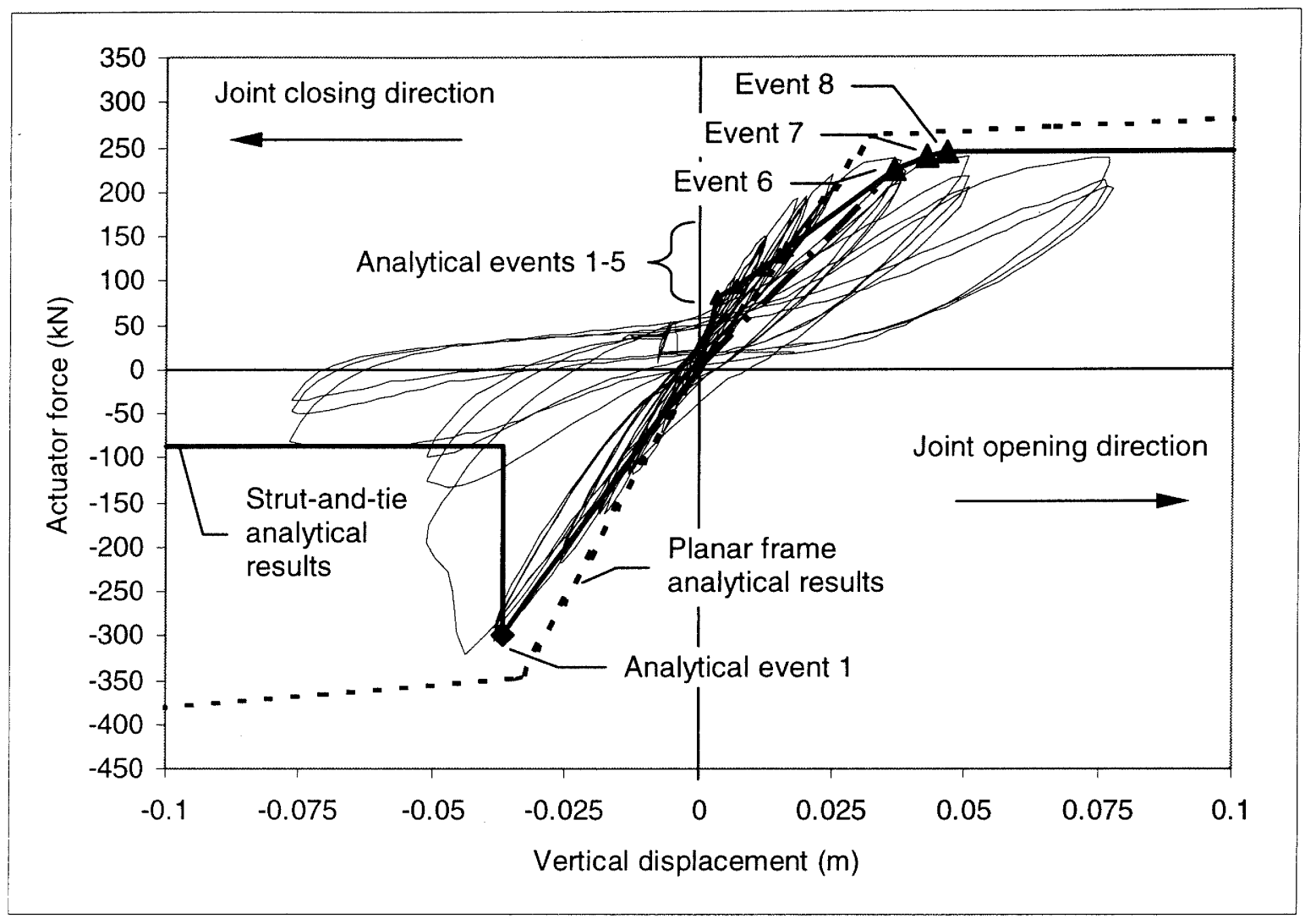

a) As-built knee-joint vertical displacement history.

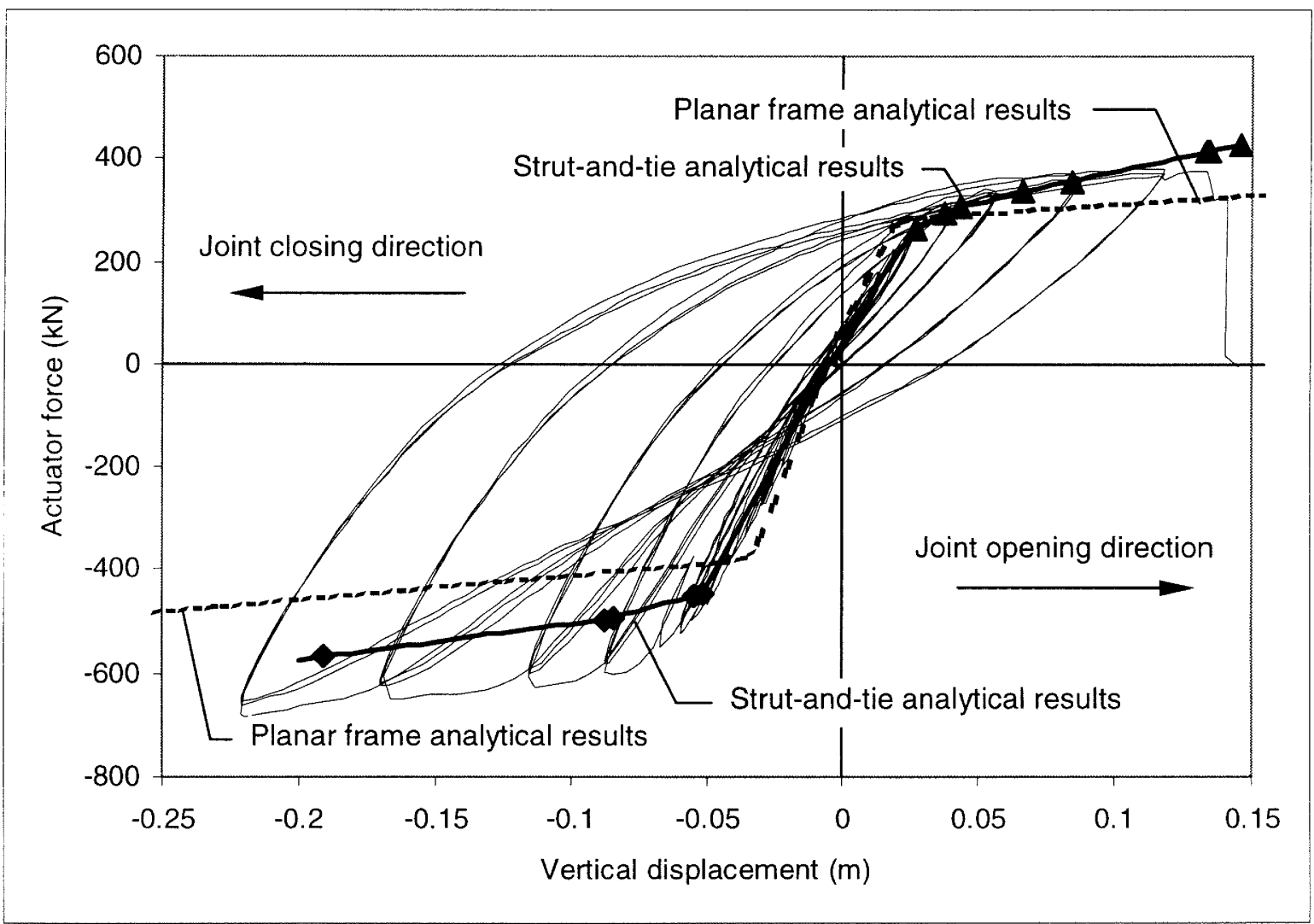

b) Repaired knee-joint vertical displacement history.

Figure 9. Correlation between test unit data and model response. 


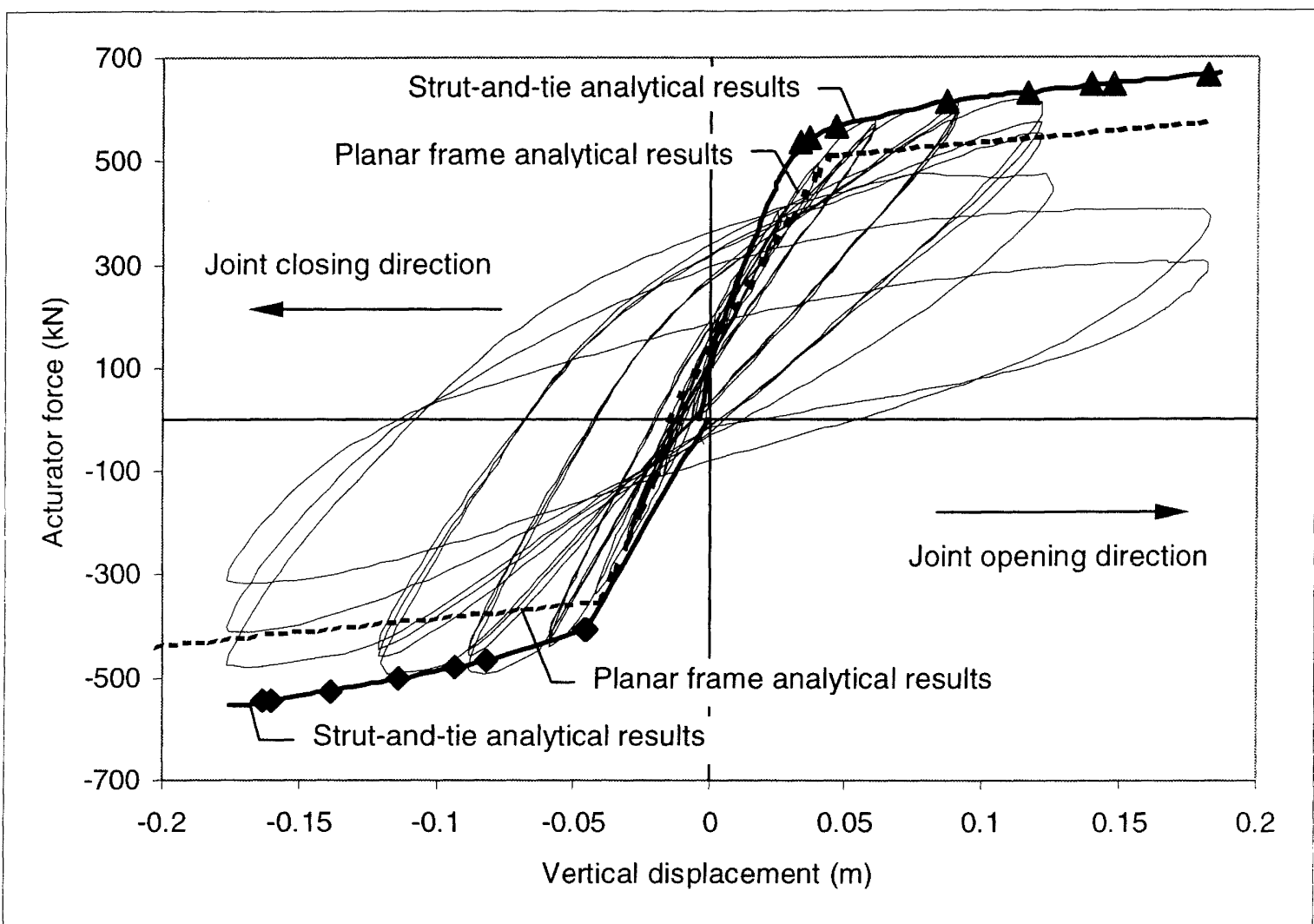

c) Retrofitted knee-joint vertical displacement history.

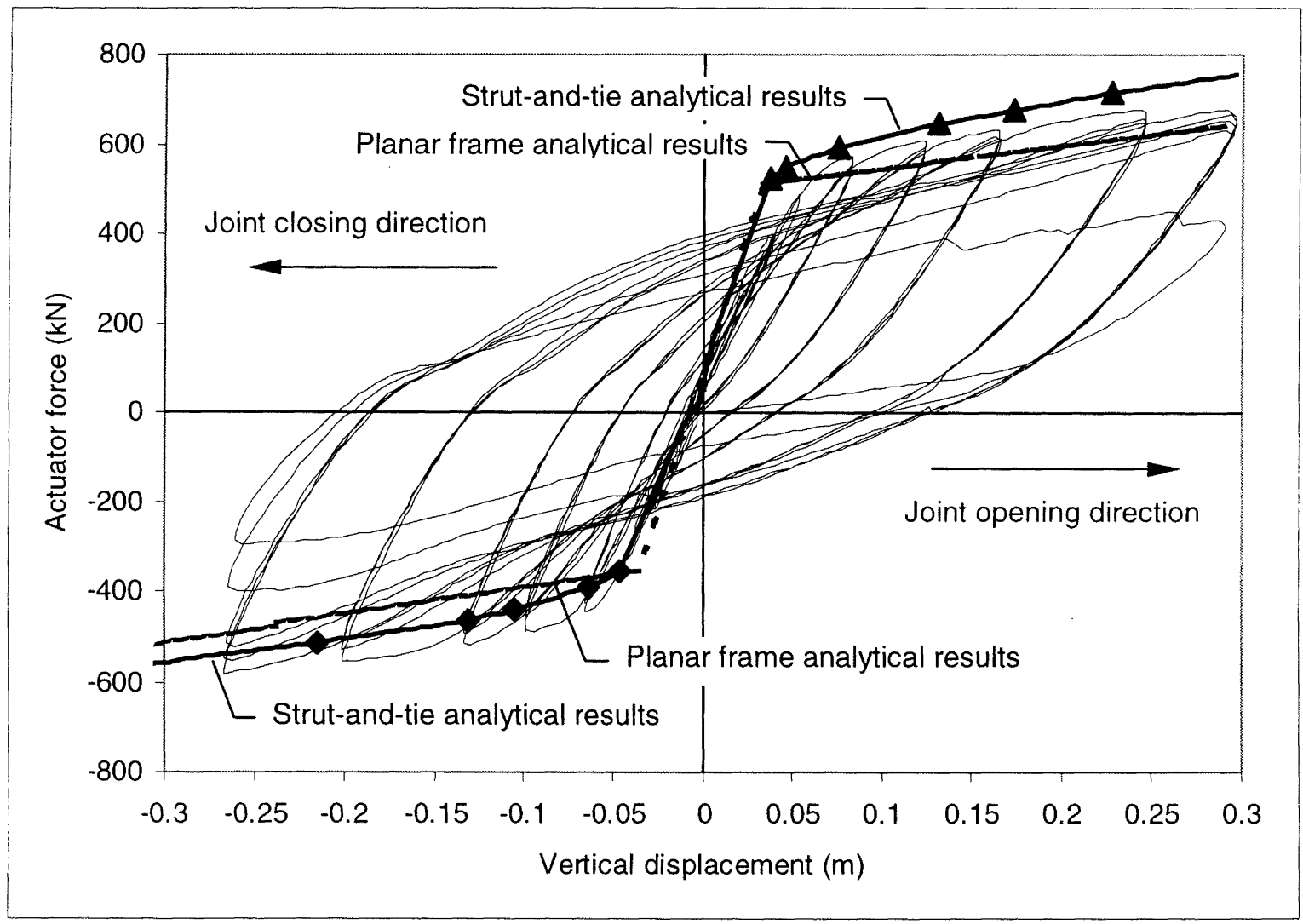

d) Redesigned knee-joint vertical displacement history.

Figure 9. Continued. 
Figs. $8 \mathrm{f}$ and $8 \mathrm{~g}$. Noteworthy features of these models are the extra struts and ties within the joint panel due to the provision of additional reinforcement, and that the enlarged joint region provided better anchorage to the embedded longitudinal reinforcement. Additionally, concrete ties were adopted in both STMs to account for the joint haunch. Since joint integrity was ensured in the repaired test unit, concrete damage in the joint region was expected to be minimal for both joint displacement directions. Therefore, $0.68 f^{\prime}$ c was adopted as the effective strength of concrete struts located in the joint panel region. Also, s.h.r. $=5.0 \%$ and $2.5 \%$ were employed for the ties representing beam and column longitudinal reinforcement, respectively.

The STM analytical results for the repaired unit in both joint displacement directions are shown in Fig. 9b using the solid lines. Excellent replication of the experimentally recorded stiffness was obtained. Also, unit strength was accurately predicted in the joint-opening direction but was underestimated by approximately $20 \%$ in the joint-closing direction. Relevant analytical events captured by the jointopening and joint-closing STMs are illustrated using solid triangles and diamonds on the respective response envelopes shown in Fig. 9b. Event 1 in the joint-opening model, shown in Fig. 8f, indicated yielding of the longitudinal reinforcement located adjacent to the beam-joint interface. This was followed by reinforcement yielding below the applied dead load and further reinforcement yielding in the beam, then cracking in the joint haunch and yielding of the joint reinforcement cage, see events $2-6$ in Fig. 8f. In addition, joint crushing was captured by event 7 at large displacement levels. For the joint-closing STM, yielding of longitudinal reinforcement first occurred in the column of Fig. 8g, followed by yielding of the longitudinal beam reinforcement located at the beam-joint interface. In general, analytical events captured by the STMs for both joint displacement directions suggested minor damage to the joint panel, which was consistent with experimental observations.

The repaired unit was also analysed using the planar frame model shown in Fig. 8e. The derived response envelopes for both joint displacement directions are illustrated in Fig. 9b using dotted lines. Analytical results were similar, but less accurate than those using the STMs. The predicted unit stiffness for both joint displacement directions was slightly greater than that observed. Furthermore, the model underestimated strength in the joint-closing directions by approximately $30 \%$. This discrepancy was partly due to the extra concrete confinement provided to the critical column section by the enlarged joint.

\subsubsection{Retrofitted unit}

The joint reinforcement details of the retrofitted unit, illustrated in Fig. 6d, were identical to those of the as-built unit. Consequently, the retrofit STMs shown in Figs. 8i and $8 \mathrm{j}$ resembled those of the as-built unit except that extra concrete was mobilised at both ends of the cap-beam to account for the prestressing. Notably, the reinforcement clamping length described using Eq. 13 was again considered when formulating the joint-opening model of Fig. 8i. Because lap-splice integrity was ensured by the applied prestressing, wide cracks causing significant strength degradation were not expected to develop in the joint panel. Therefore, $0.51 f^{\prime}$ c was adopted as the compressive strength of concrete struts locating in the joint panel region. Again, s.h.r.
$=5 \%$ and $2.5 \%$ were employed for the ties representing beam and column longitudinal reinforcement, respectively.

The force-displacement response envelopes generated using the two STMs are illustrated in Fig. 9c using solid lines. Analytical results indicated satisfactory correlation to the experimental records except for minor overestimation of the stiffness for joint-opening actions.

Analytical events captured by the STMs for both joint displacement directions are illustrated using solid triangles and diamonds on the respective force-displacement response envelopes shown in Fig. 9c. In the joint-opening model, yielding first occurred in the column longitudinal reinforcement as indicated by event 1 and then concrete crushing was predicted by event 2 in Fig. 8i. Subsequent analytical events 3-8 in Fig. $8 \mathrm{i}$ suggested yielding of the column longitudinal reinforcement and of the beam longitudinal reinforcement locating adjacent to the applied dead load. For the joint-closing model, a similar event sequence was predicted. Yielding of the column longitudinal reinforcement first developed, see events $1-3$, followed by concrete crushing in the joint panel, see event 4 in Fig. 8 j. Yielding of beam reinforcement located adjacent to the beam-joint interface was next predicted, see events 5-6 in Fig. $8 \mathrm{j}$. This was following by further yielding of column longitudinal reinforcement as captured by event 7 shown in Fig. 8j. In addition, event 8 indicated that concrete crushing at the column-joint interface developed at a large displacement level.

It is noteworthy that reinforcement plasticity was predicted in column and beam members for both joint displacement directions, but that vertical displacements were largely attributable to column flexural deformation. Analytical events captured by the STMs were generally consistent with experimental observations.

An analysis using the planar frame model shown in Fig. $8 \mathrm{~h}$ was also implemented. The force-displacement response envelope generated using the frame model is illustrated in Fig. 9c using dotted lines. Results indicated satisfactory correlation with the experimentally recorded stiffness and unit strength for both joint displacement directions

\subsubsection{Redesigned unit}

The redesigned test unit had an identical column to the asbuilt unit, but was constructed with different beam and joint reinforcement details, see Fig. 6e. Extra longitudinal reinforcement was allocated in the top of the beam section to enhance the negative flexural strength. Capacity design philosophy was employed in designing the joint, based on the joint reinforcement approaching its yield strength when the column developed its flexural strength. In addition, the embedded longitudinal reinforcement was bent within the joint panel to provide effective anchorage and allow a superior force transfer mechanism to be developed. On this basis the STMs for both joint displacement directions, depicted in Figs. $8 \ell$ and $8 \mathrm{~m}$, were formulated. Since the joint was fully reinforced and was expected to develop minimal damage, $0.68 f^{\prime}$ c was adopted as the effective strength of concrete struts locating in the joint panel region. Because the beam member was reinforced with significant side reinforcement, s.h.r $=2.5 \%$ was employed for ties representing both beam and column longitudinal reinforcement. 
The force-displacement envelopes obtained from STMs for joint-opening and joint-closing actions are illustrated in Fig. $9 \mathrm{~d}$ using solid lines. Analytical results provided satisfactory correlation to the experimental records, except that unit stiffness in the joint-opening direction was slightly overestimated. Analytical events captured by the STMs are illustrated using solid triangles and diamonds on the respective force displacement envelope in Fig. 9d. As shown in Fig. $8 \ell$, events 1-6 suggested plasticity only occurred in the column longitudinal reinforcement. For the joint-closing model, events 1-3 in Fig. $8 \mathrm{~m}$ predicted that yielding of column longitudinal reinforcement first occurred. This was followed by events $4-5$ suggesting plasticity developed in the beam longitudinal reinforcement, along with further yielding of the column longitudinal reinforcement. Event 6 indicated yielding of a tie representing reinforcement in the joint panel. This was consistent with the expected performance of the test.

It is noteworthy that extensive concrete damage along the right column face, observed in the test unit, was not captured by the STMs. However, as the joint-opening model suggested significant inelastic strain in the column longitudinal reinforcement, damage to concrete at the corresponding location was highly possible.

The planar frame model shown in Fig. 8k was also studied. The force-displacement response envelopes for both joint displacement directions analysed using the planar frame model are shown in Fig. 9d using dotted lines. Analyses indicated slight stiffness overestimation for both joint opening and closing actions, but that unit strength was reasonably captured.

\subsection{CONCLUSIONS}

The non-linear strut-and-tie formulation procedure for column and beam members was demonstrated. This method was incorporated with previously developed knee-joint STMs to reproduce the observed structural performance of four knee-joint test units.

Analytical charts were generated for typical nominal material strengths to assist the formulation of the beam or column STM. Satisfactory prediction of the non-linear structural response was obtained by locating the strut and the tie members at the corresponding flexural force centroids measured at the first yield state.

Good correlation between the observed response of kneejoint test units in the laboratory and that predicted confirms that the non-linear strut-and-tie method of analysis represents an effective tool for assessing demand upon various elements within a structure. It has been shown that the location of reinforcement yielding and lap-splice failure can be captured by the rational STM.

It is apparent that the strut-and-tie analysis is superior to the conventional frame analysis since it can predict joint failure by examining the capacity of rational force transfer mechanisms. However, the greater complexity of the STM will probably be a significant impediment limiting its application in design practice.

\subsection{ACKNOWLEDGEMENTS}

Financial assistance from NZSEE, through a student research scholarship to the primary author, is gratefully acknowledged.

\subsection{REFERENCES}

1. Schlaich, J., Schafer, K., and Jennewein, M. (1987), "Toward a Consistent Design of Structural Concrete", PCI Journal, Vol. 32, No. 3, May-June, pp. 74-151.

2. ACI Committee 445 - Shear and Torsion (1997) "Strutand-Tie Bibliography", ACI Bibliography No. 16, September, 50p.

3. Ingham, J. M., Priestley, M. J. N. and Seible, F. (1997), "Seismic Response of Bridge Knee Joints having Columns with Interlocking Spirals", Bulletin of NZ National Society for Earthquake Engineering, Vol. 30, No. 2, June, pp. 114-132.

4. Ingham, J. M., Priestley, M. J. N. and Seible, F. (1994), "Seismic Performance of Bridge Knee Joints - Volume 1, Rectangular Column/Cap Beam Experimental Results", Report SSRP-94/12, Department of Applied Mechanics and Engineering Sciences, University of California at San Diego, La Jolla, California, June, $277 \mathrm{p}$.

5. Mander, J.B., Priestley, M. J. N. and Park, R. (1988), "Theoretical Stress-Strain Model for Confined Concrete", Journal of Structural Engineering, ASCE. Vol. 114, No. 8, August, pp. 1805-1826.

6. "Eurocode 2: Design of concrete structures Part 1: General rules and rules for buildings", European Committee for Standardization (CEN), ENV 1992-1-1: 1991, 253p.

7. NZS 3101:1995, "Code of Practice for the Design of Concrete Structures", Standards Association of New Zealand (1995) Wellington, 264p.

8. "CEB-FIP Model Code for Concrete Structures", $3^{\text {rd }}$ Edition, Comité Euro-International du Béton/Fédération Internationale de la Précontrainte, Paris, 1978, 348p.

9. Kim, J. H. and Mander, J. B. (1999), "Truss Modeling of Reinforced Concrete Shear-Flexural Behaviour", Technical Report MCEER-99-0005, Department of Civil, Structural and Environmental Engineering, University of New York at Buffalo, Buffalo, New York, March, 212p.

10. Collins, M. P. and Mitchell D. (1980), "Design proposals for shear and torsion", Journal of the Prestressed Concrete Institute, Vol. 25, No. 5, SeptOct, pp.32-74.

11. Priestley, M. J. N., Seible, F. and Calvi, G. M. (1996), "Seismic Design and Retrofit of Bridges", John Wiley \& Sons, Inc., New York, 333p. 
12. Ang, B. G., Priestley, M. J. N. and Paulay, T. (1989), "Seismic Shear Strength of Circular Reinforced Concrete Columns", ACI Structural Journal, Vol. 86, No. 1, January/February, pp. 45-59.

13. Rogowsky, D. M. and MacGregor, J. G. (1986), "Design of Deep Reinforced Concrete Continuous Beams", Concrete International: Design and Construction, Vol. 8, No. 8, August, pp. 49-58.

14. Sritharan, S. (1998), "Analysis of Concrete Bridge Joints Subjected to Seismic Actions", Doctoral Dissertation, Department of Applied Mechanics and Engineering Sciences, University of California at San Diego, La Jolla, California, June, 407p.

15. Liddell, D., Ingham, J. M. and Davidson, B. J. (2000), "Influence of Loading History on Ultimate Displacement of Concrete Structure", Report No. 597, Department of Civil and Resource Engineering, University of Auckland, New Zealand, July, 263p.

\section{APPENDIX A - LIST OF SYMBOLS}

$A_{c: s} \quad$ cross-section area of longitudinal concrete struts;

$A_{e} \quad$ effective shear area;

$A_{g} \quad$ gross sectional area;

$A_{r: s} \quad$ cross-section area of longitudinal rebar struts;

$A_{r \prime} \quad$ cross-section area of ties representing longitudinal reinforcement;

$A_{a} \quad$ tension reinforcement area;

$A_{s}^{\prime} \quad$ compression reinforcement area;

$A_{s t} \quad$ total longitudinal reinforcement area;

$A_{1} \quad \quad$ cross-section area of ties representing transverse reinforcement;

$A_{v: s} \quad$ transverse reinforcing steel bars cross-sectional area;

$b_{0}$ the width of rectangular concrete core measured from the inner face to inner face of peripheral hoops or spirals;

$b_{w} \quad$ section web width;

$c \quad$ neutral axis depth;

$C_{\imath}$ (mix) maximum possible concrete compression obtained from the sectional force analysis;

d effective sectional depth;

$d_{b}$ diameter of longitudinal rebar;

$d_{1 *} \quad$ diameter of transverse rebar;

D total sectional depth for rectangular column or sectional diameter for circular column:

$D^{\prime} \quad$ diameter of circular concrete core measured from centre to centre of peripheral hoop;
$D_{0} \quad$ the depth of rectangular concrete core measured from inner face to inner face of the peripheral hoop;

$E_{c} \quad$ Young's modulus of structural concrete;

$E A_{g} \quad$ gross axial stiffness;

$E I_{\varkappa} \quad$ effective flexural stiffness;

$E I_{g} \quad$ gross flexural stiffness;

$f_{\mathrm{c}}^{\prime} \quad$ unconfined concrete compressive strength;

$f_{d} \quad$ effective strength of concrete strut;

$f_{e v} \quad$ effective yield strength of ties representing longitudinal reinforcement;

$f_{v y} \quad$ tensile strength of transverse reinforcement;

$f_{y} \quad$ reinforcement yield strength;

$\ell_{c} \quad$ reinforcement clamping length;

$\ell_{p j} \quad$ yield penetration length into the joint region;

$\ell$. lap splice length of the longitudinal rebars;

$M^{l s t}{ }_{\text {y }} \quad$ first yield state moment;

$p_{i} \quad$ cross-sectional length of the lap splice rupture surface;

$r_{0} \quad$ radius of circular concrete core measured from section centre to the inner face of peripheral spiral or hoop

longitudinal distance between transverse reinforcement;

the thickness of a longitudinal steel tube represents the approximately uniformly distributed longitudinal rebar in column section;

$T \quad$ total steel tension when the extreme rebar reaches the yield strength;

$T_{t p} \quad$ capacity of lap splicing;

$V_{s} \quad$ transverse rebar contribution to the member shear strength;

$\alpha \quad$ half angle of the tension sector;

$\phi^{l s t}{ }_{y} \quad$ first yield state curvature

$\rho_{l} \quad$ total longitudinal reinforcement quantity

$\rho_{\mathrm{w}} \quad$ area ratio of longitudinal tension reinforcement to gross sectional area;

$\sigma_{s}$ the stress function along the imaginary longitudinal steel tube, assuming a linear stress distribution profile; 


\section{APPENDIX B - SECTION FORCE ANALYSIS CHARTS}

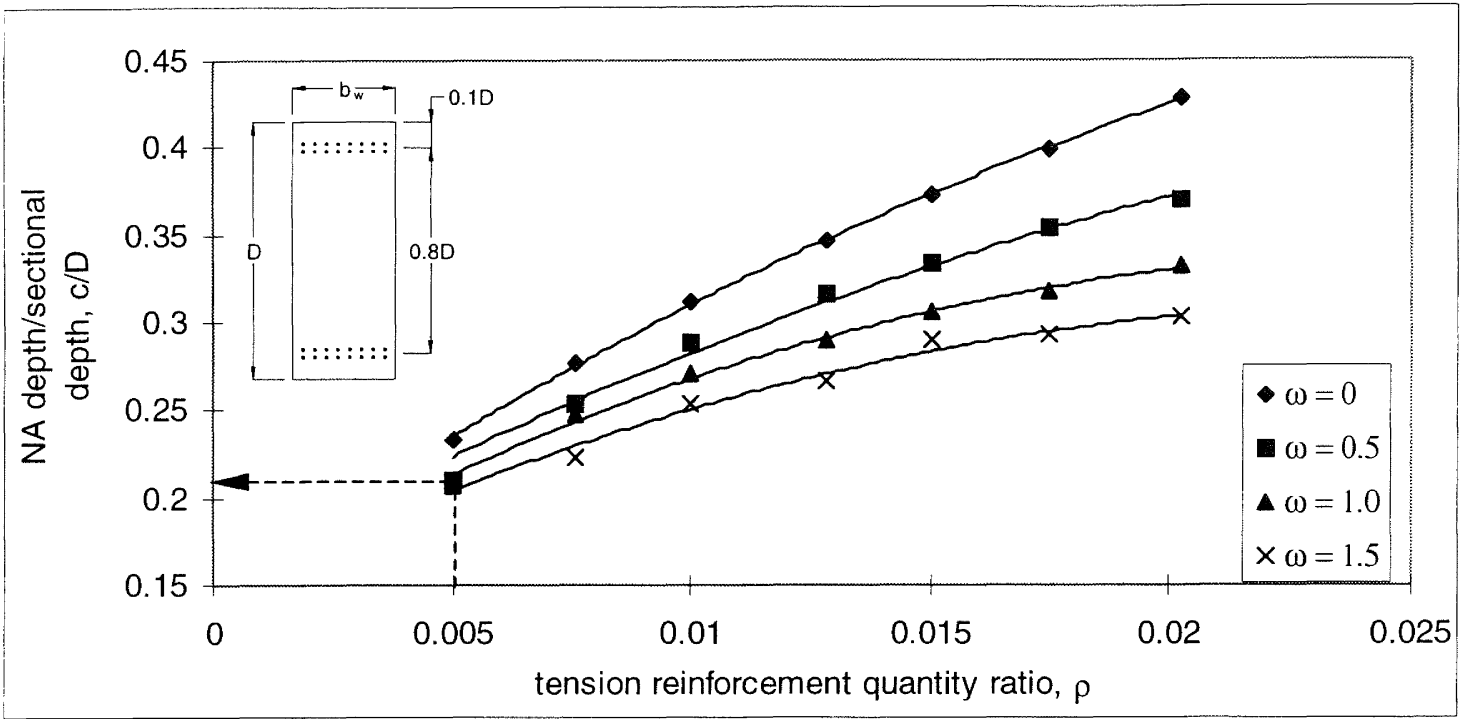

B1.1) Beam section neutral axis position at the first yield state, $f_{c}{ }_{c}=30 \mathrm{MPa}$.

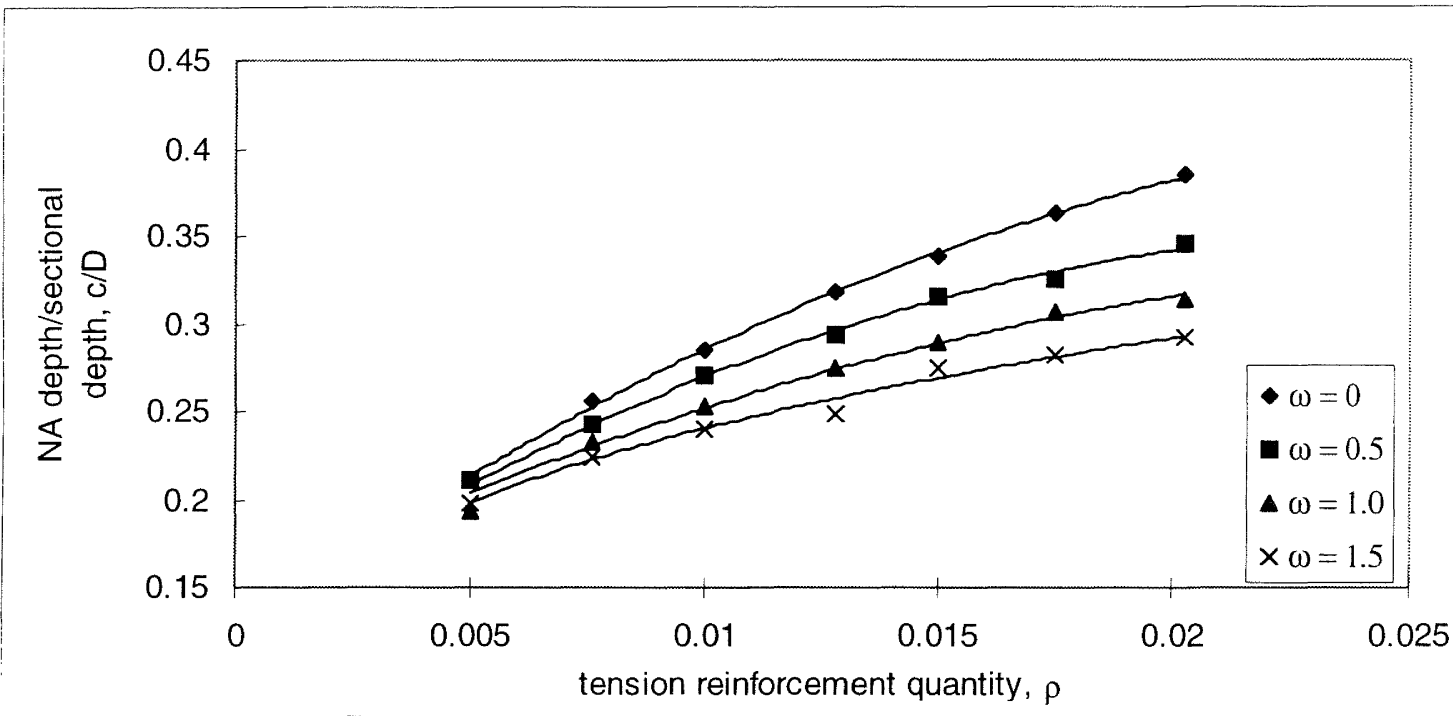

B1.2) Beam section neutral axis position at the first yield state, $f_{c}^{\prime}=40 \mathrm{MPa}$.

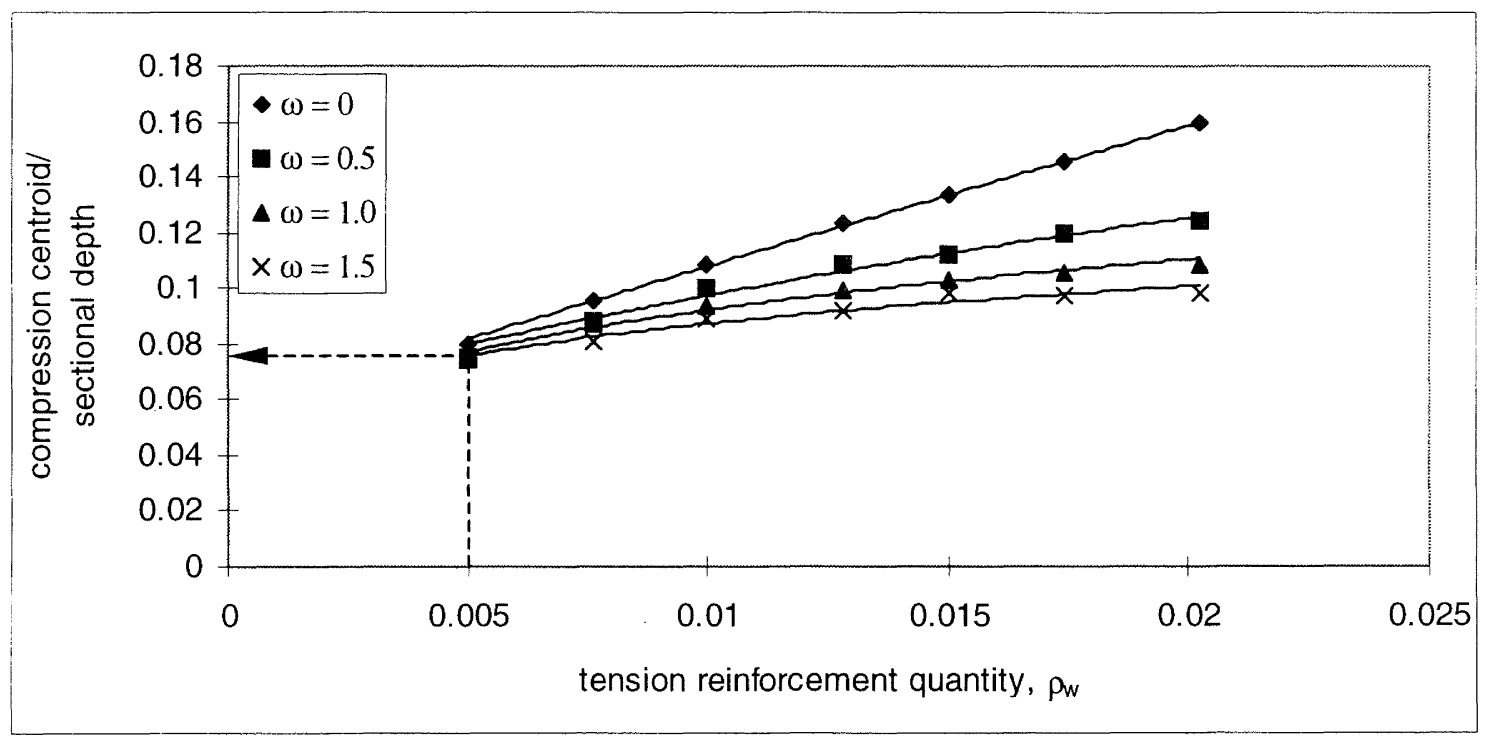

B1.3) Beam section compression centroid position at the first yield state, $f_{c}^{\prime}=30 \mathrm{MPa}$. 


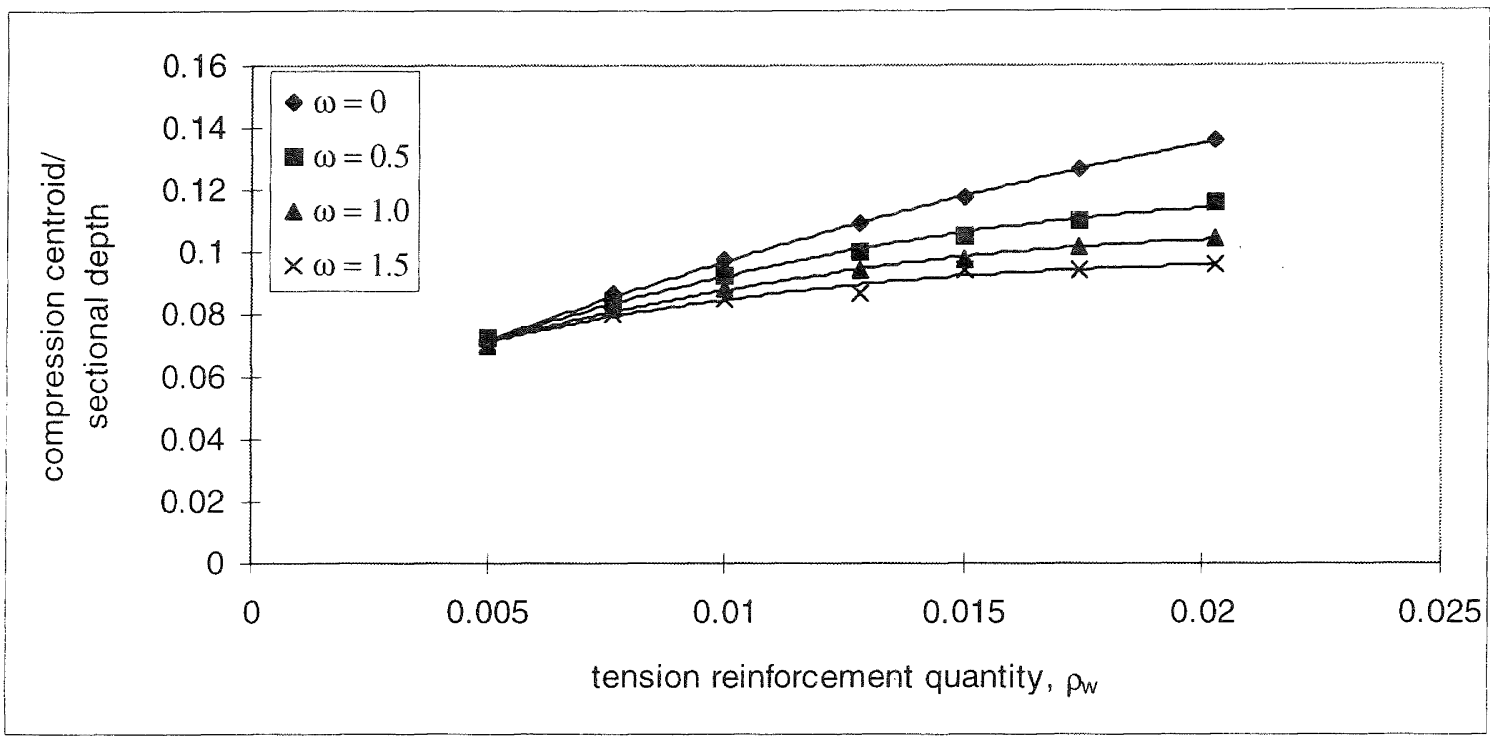

B1.4) Beam section compression centroid position at the first yield state, $f_{c}^{\prime}=40 \mathrm{MPa}$.

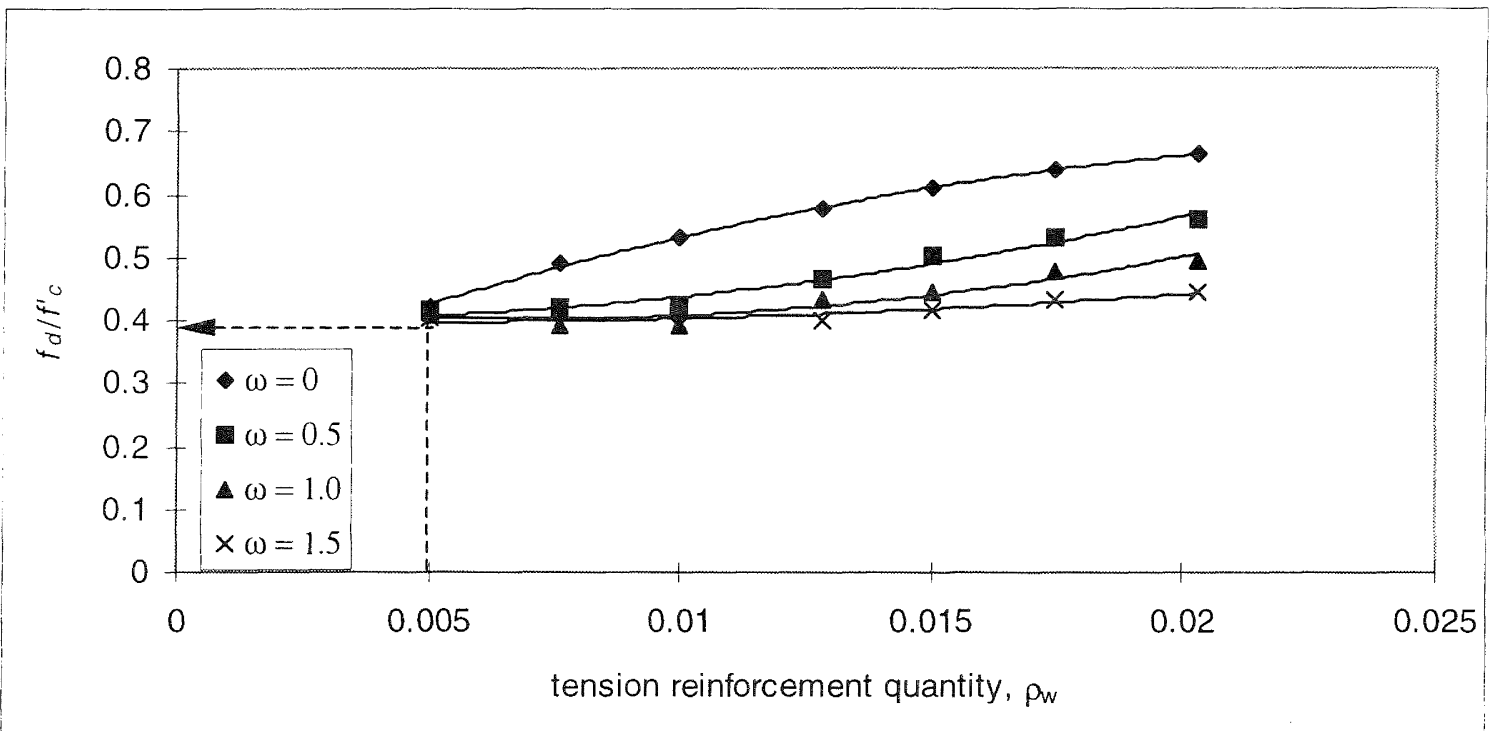

B1.5) Beam section effective concrete compressive strength, $f_{c}^{\prime}=30 \mathrm{MPa}$.

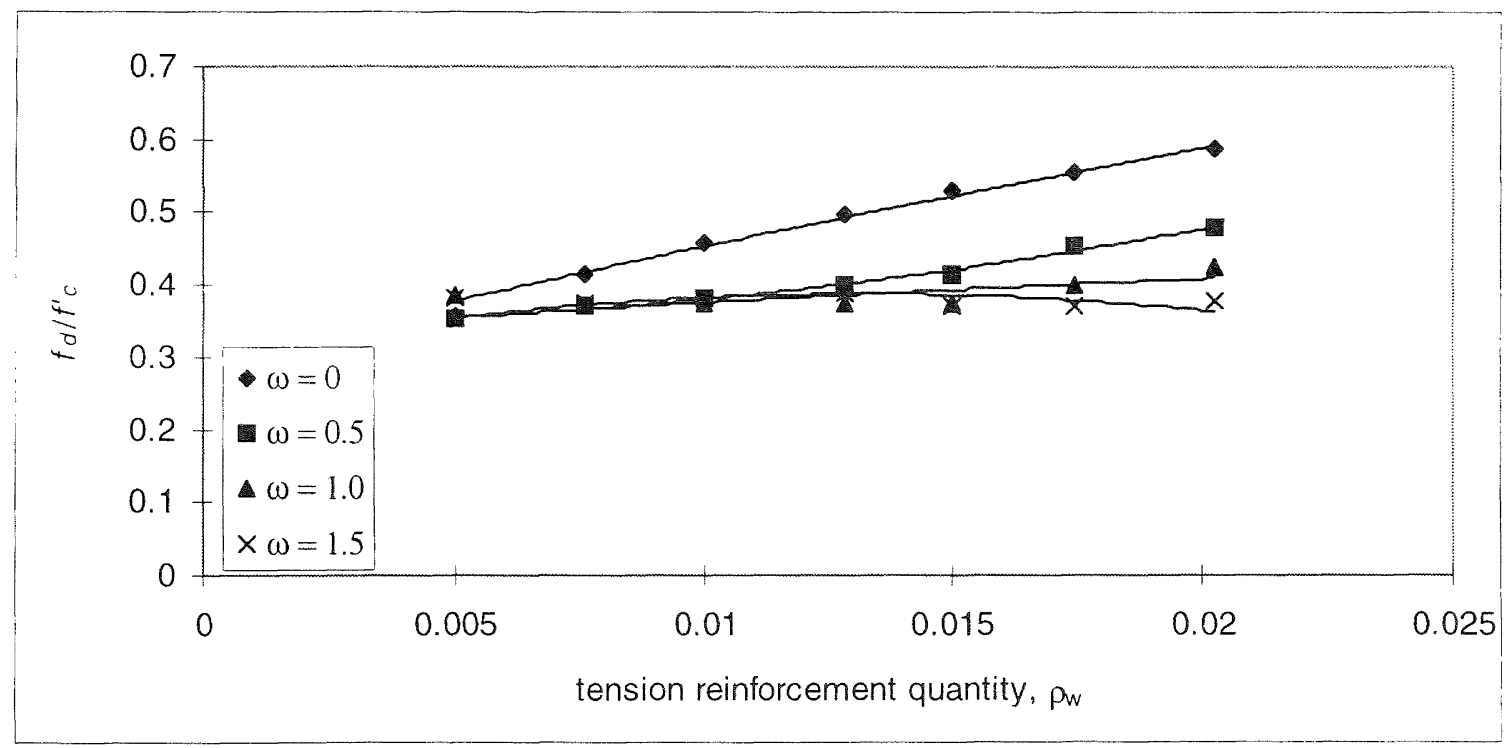

B1.6) Beam section effective concrete compressive strength, $f^{\prime}{ }_{c}=40 \mathrm{MPa}$. 


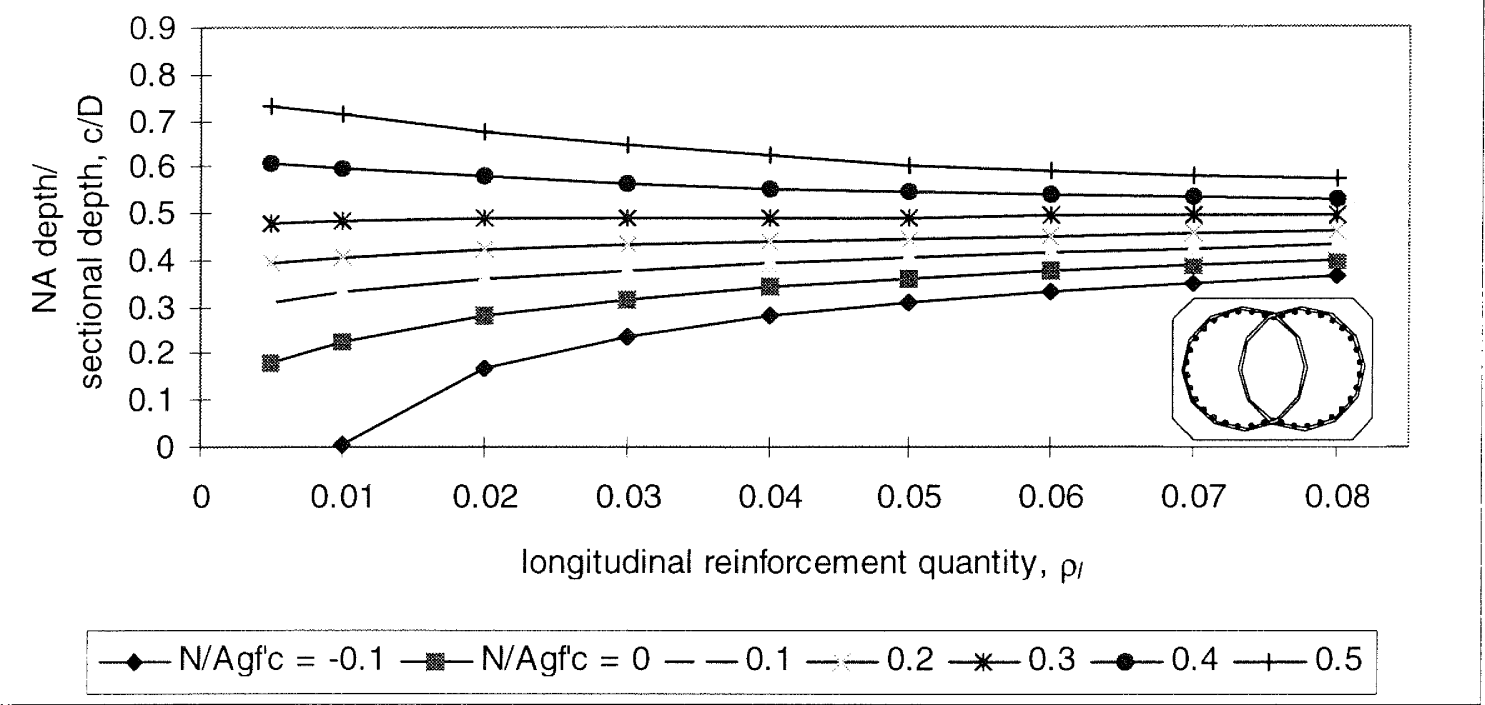

B2.1) Column section neutral axis position at the first yield state, ${f^{\prime}}_{c}=30 \mathrm{MPa}$.

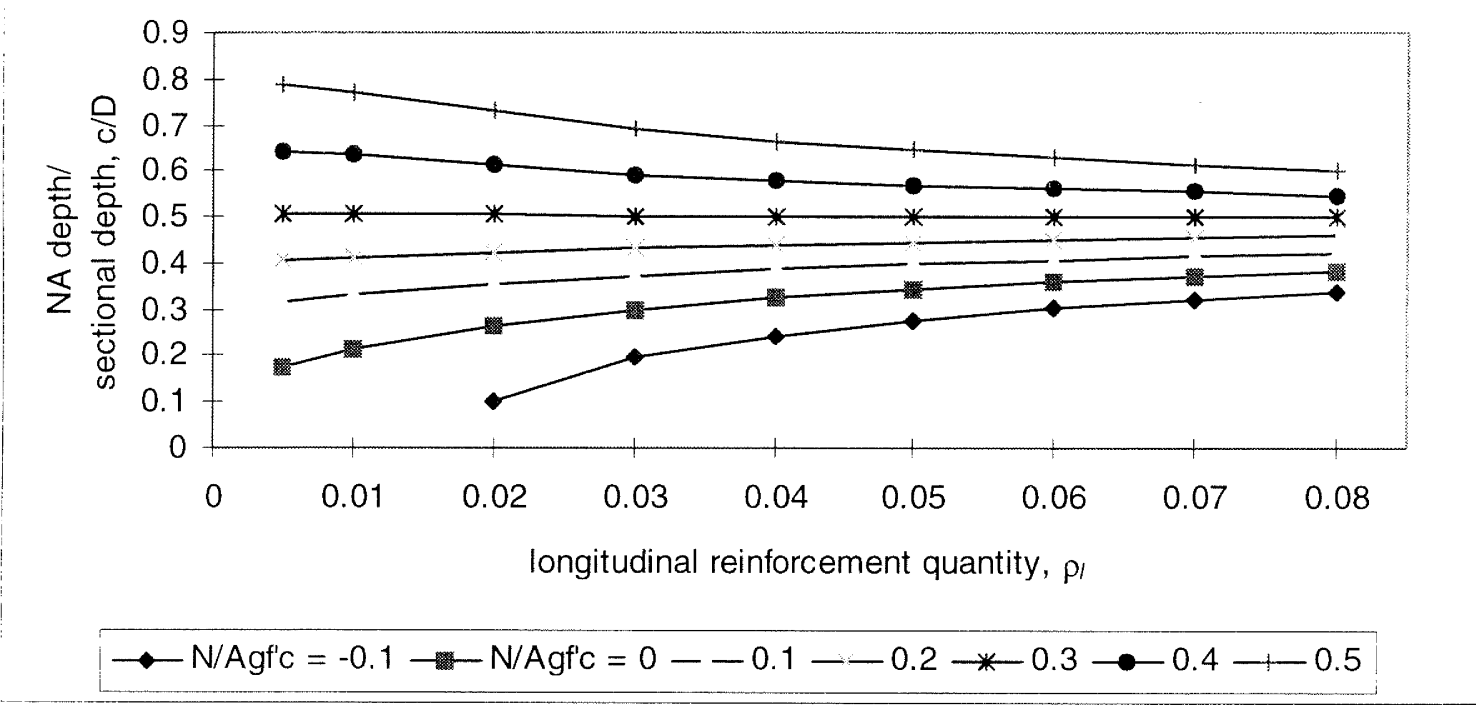

B2.2) Column section neutral axis position at the first yield state, ${f^{\prime}}_{c}=40 \mathrm{MPa}$.

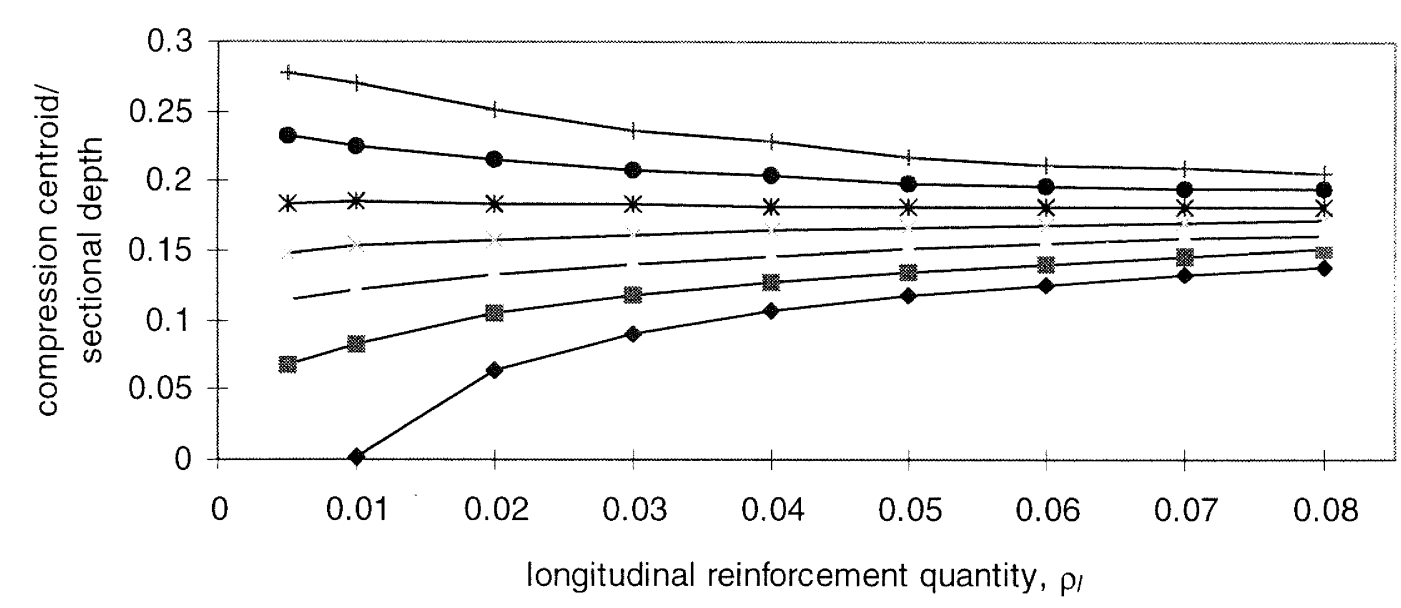

$\longrightarrow \mathrm{N} /$ Agf'c $=-0.1 \rightarrow-\mathrm{N} /$ Agf'c $=0--0.1 \longrightarrow-0.2 \rightarrow 0.3 \rightarrow 0.4 \multimap 0.5$

B2.3) Column section compression centroid position at the first yield state, $f_{c}^{\prime}=30 \mathrm{MPa}$. 


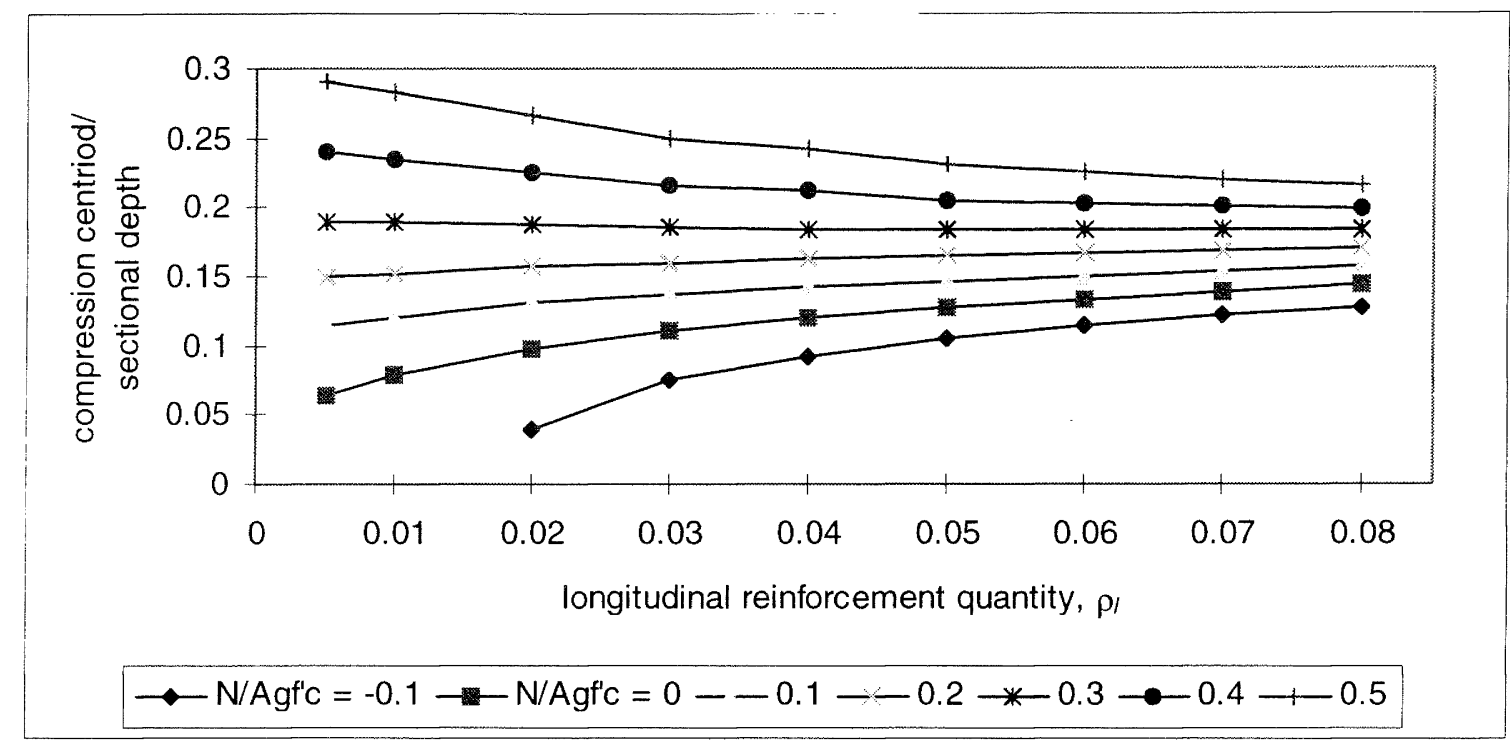

B2.4) Column section compression centroid position at the first yield state, $f^{\prime}{ }_{c}=40 \mathrm{MPa}$.

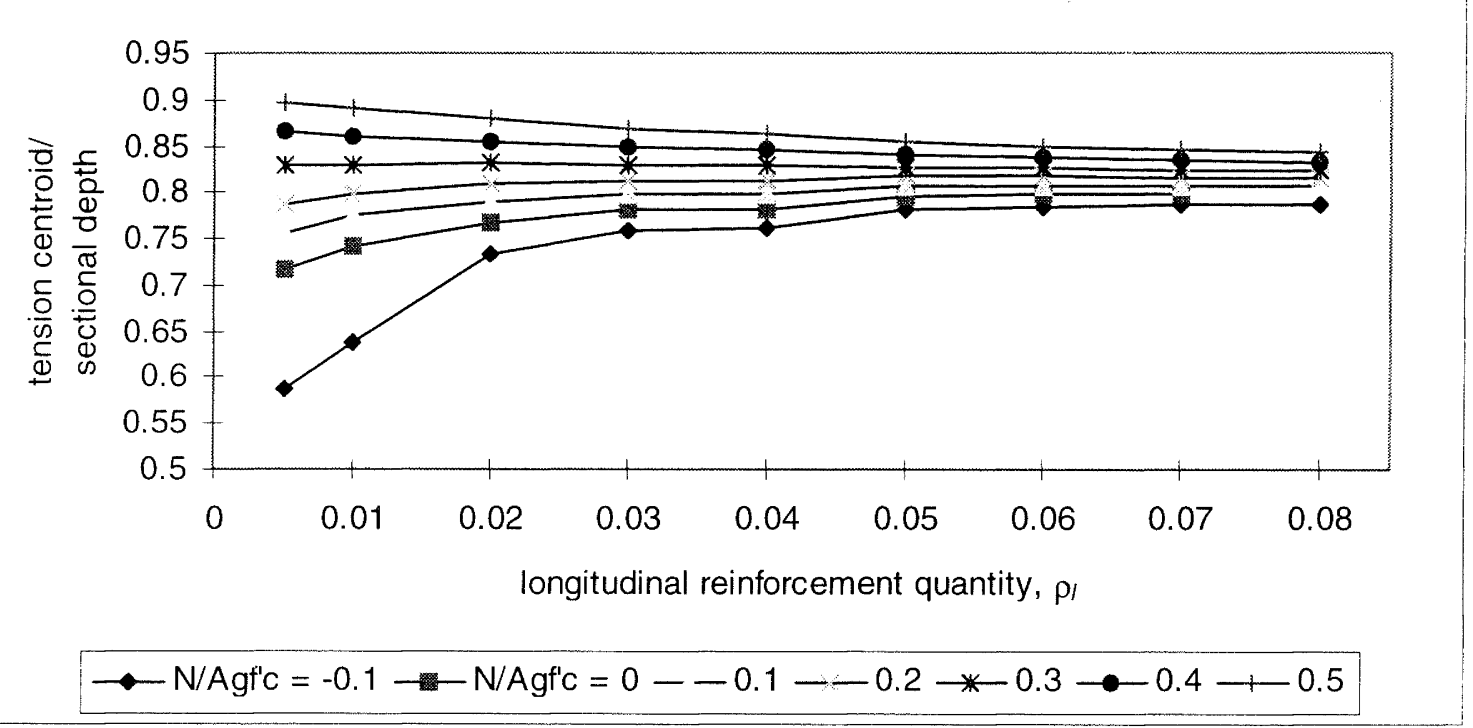

B2.5) Column section tension centroid position at the first yield state, $f^{\prime}{ }_{c}=30 \mathrm{MPa}$.

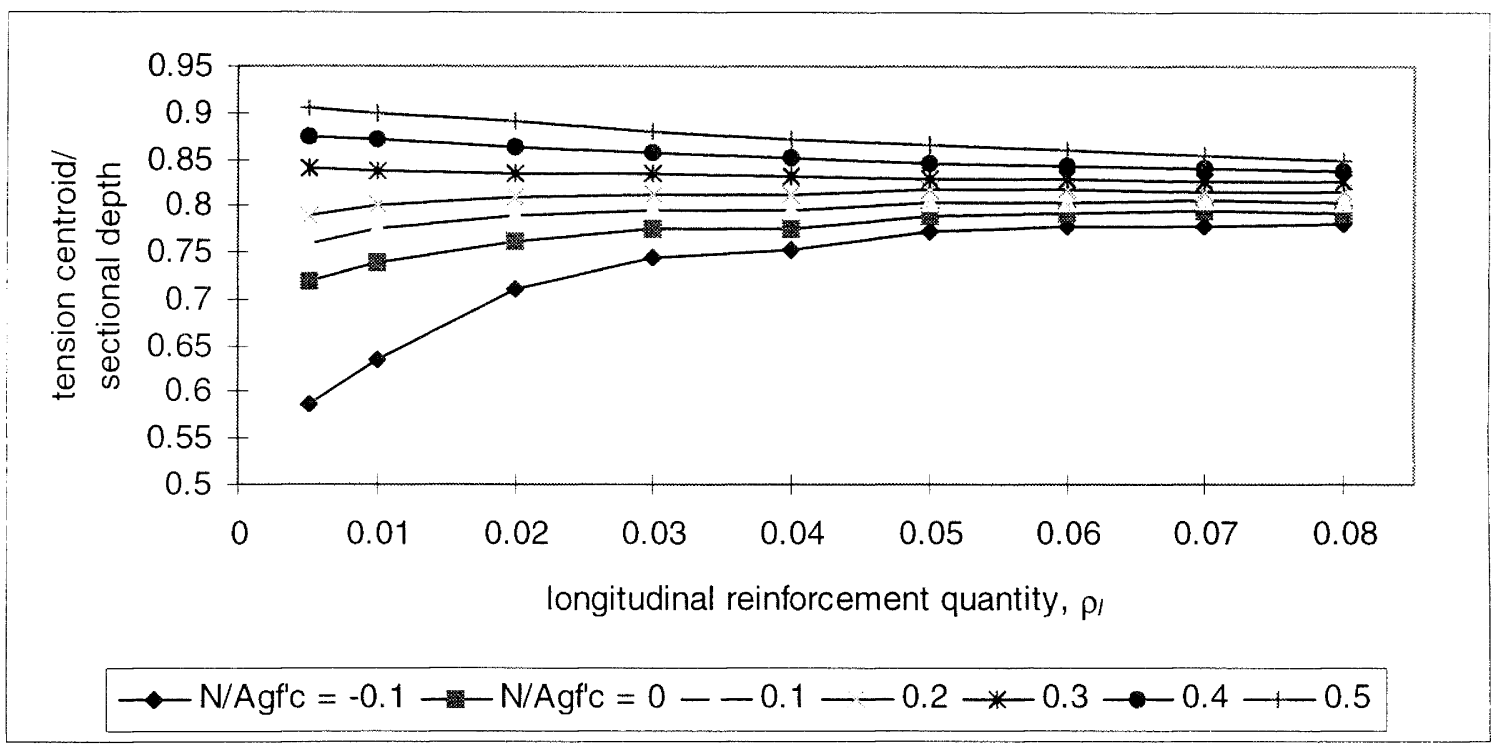

B2.6) Column section tension centroid position at the first yield state, $f_{c}^{\prime}=40 \mathrm{MPa}$. 


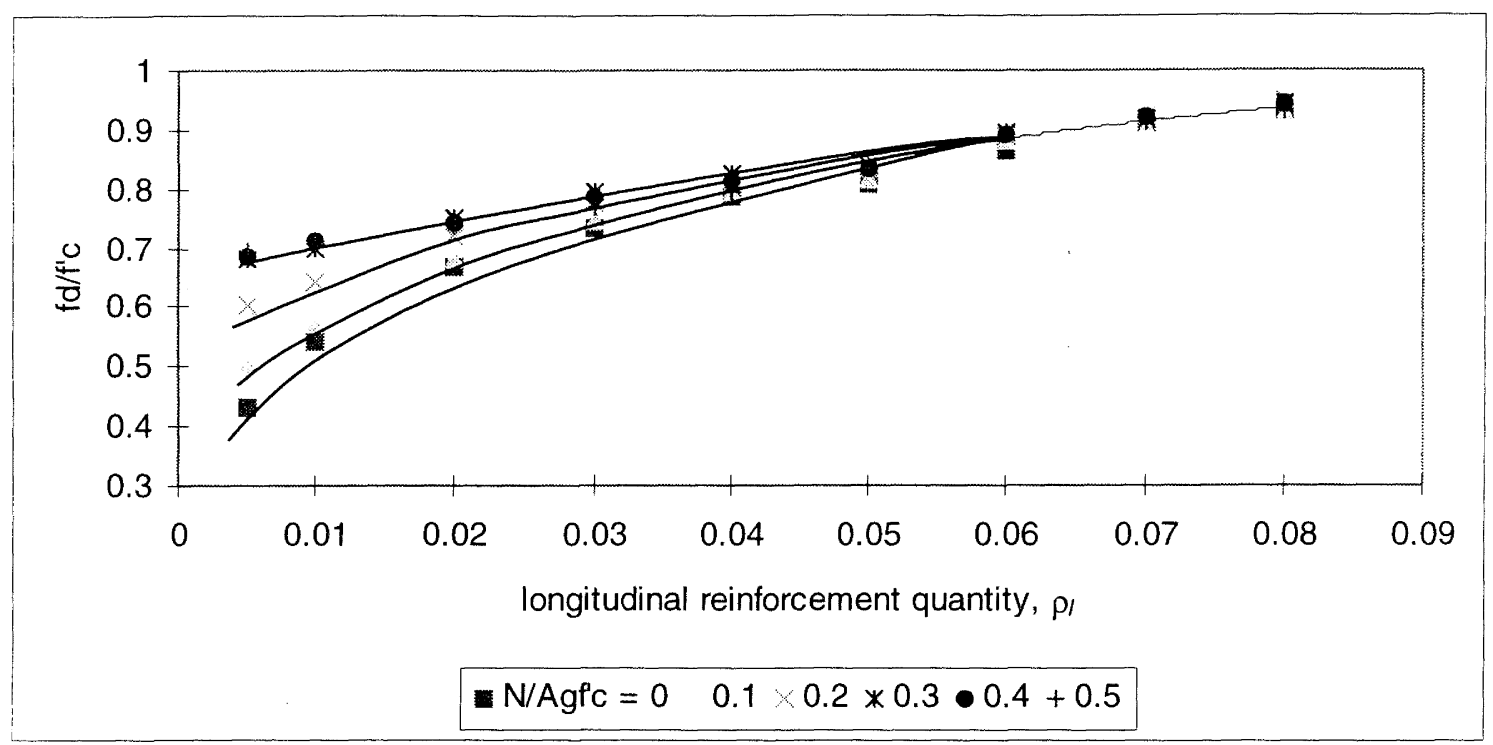

B2.7) Column section effective concrete compressive strength, $f_{c}^{\prime}=30 \mathrm{MPa}$.

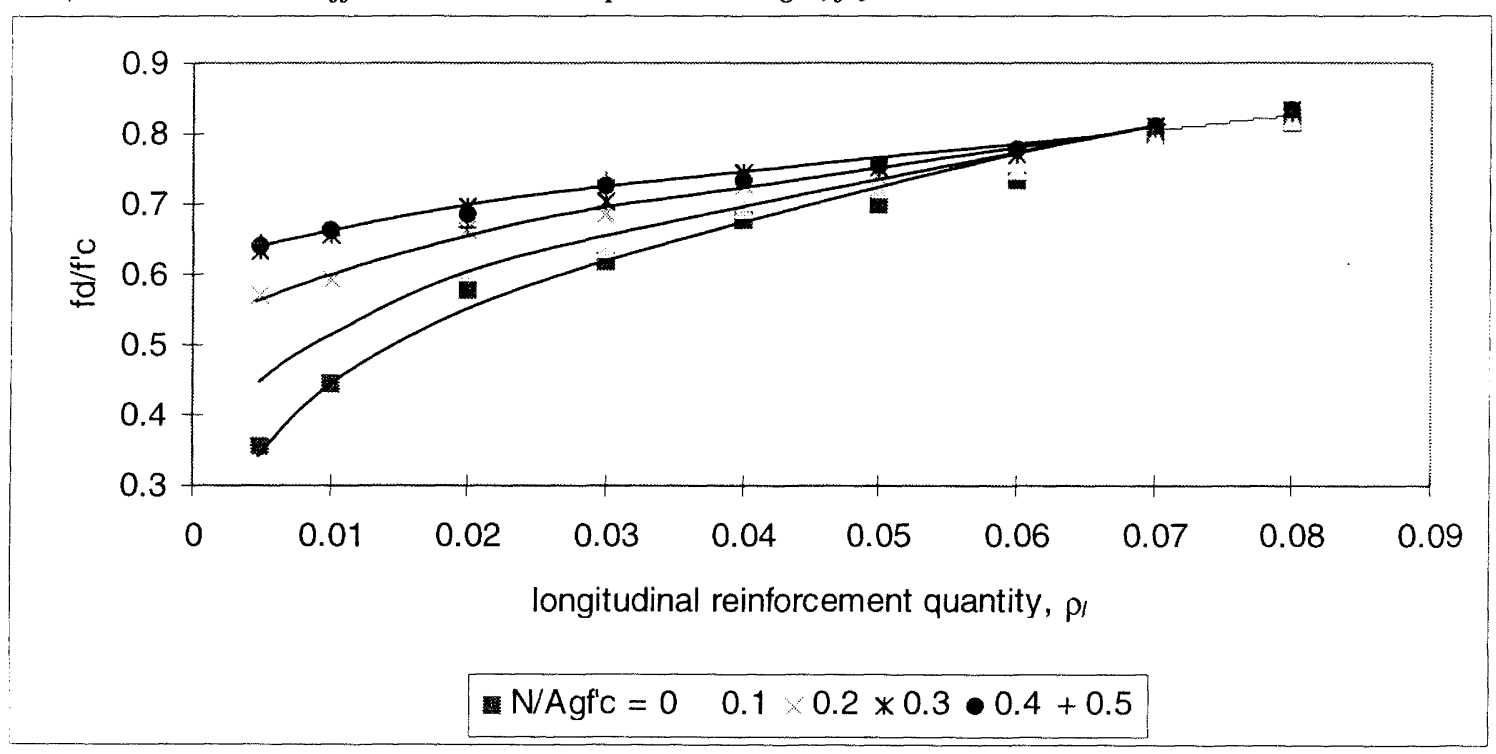

B2.8) Column section effective concrete compressive strength, $f_{c}^{\prime}=40 \mathrm{MPa}$. 